\title{
Numerical simulation of elasto-plastic electro-osmosis consolidation at large strain
}

\author{
Jiao Yuan · Michael A. Hicks
}

Received: 1 November 2013/Accepted: 8 January 2015/Published online: 8 February 2015

(C) The Author(s) 2015. This article is published with open access at Springerlink.com

\begin{abstract}
In this paper, a numerical solution for the electro-osmosis consolidation of clay in multi-dimensional domains at large strains is presented, with the coupling of the soil mechanical behaviour, pore water transport and electrical fields being considered. In particular, the Modified Cam Clay model is employed to describe the elastoplastic behaviour of clay, and some empirical expressions are used to consider the nonlinear variation of the hydraulic and electrical conductivities of the soil mass during the consolidation processes. The implementation of the theoretical model in a finite element code allows for analysis of the evolution of the transient response of the clay subjected to electro-osmosis treatment. The proposed model is verified via comparison with data from a large strain electroosmosis laboratory test, to demonstrate its accuracy and effectiveness. Various numerical examples are also investigated to study the deformation characteristics and timedependent evolution of the excess pore pressure. Finally, a well-documented field application of electro-osmosis is simulated to provide further verification. The results show that the numerical solution is effective in predicting the nonlinear behaviour of clay during electro-osmosis consolidation.
\end{abstract}

Keywords Elasto-plastic - Electro-osmosis consolidation · Finite element analysis · Ground settlement · Large strain

\footnotetext{
J. Yuan · M. A. Hicks ( $\square)$

Section of Geo-Engineering, Department of Geoscience and Engineering, Faculty of Civil Engineering and Geosciences, Delft University of Technology, P.O. Box 5048, 2600 GA Delft, The Netherlands

e-mail: M.A.Hicks@tudelft.nl

J. Yuan

e-mail: J.Yuan-1@tudelft.nl
}

\section{Introduction}

A wide variety of ground improvement methods have been developed for economic foundation solutions on soft soils (for a state-of-the-art, see [15] and cited references). An alternative method, however, is the use of electroosmosis. Electro-osmosis is important for many geotechnical applications, such as improving friction pile capacity, preventing excessive foundation deformations, strengthening and stabilization of soft clays, controlling pore water pressures at excavation sites, consolidation of marine sediments for land reclamations and dewatering of mine tailings $[7,8,11,20,21,27,28,30]$. At the same time, numerous laboratory studies have been reported to understand the suitability of the application; the anticipated effects of the treatment, its efficiency and effectiveness, and so on, for different types of soil $[4,6,10$, $13,14,22,23,28,32,37,38]$. Electro-osmosis is also a promising method for the remediation of low permeability clays and silts. It is therefore important for many geoenvironmental applications, and the mechanism of electro-osmosis remediation treatment has been carefully studied [1, 3-5, 48]. Recent laboratory studies and modelling approaches have focussed on the electro-chemical behaviour of soils $[2,12,46]$.

Consolidation of clays due to applying an electric current may occur as the result of two distinct mechanisms: osmosis under electric gradients will cause fluid flow from the anode to the cathode, resulting in pore pressure changes and a consequential increase in effective stress in the clay; a less important effect is the hardening of the soil due to the generation of heat and electro-chemical reactions during the process. Electro-osmosis consolidation is a coupled process involving mechanical behaviour, hydraulic flow and electrical flow. 
The theory of one-dimensional (1D) electro-osmosis consolidation was first developed by Esrig [18], and, based on Esrig's equation, Wan and Mitchell [47] presented an analytical solution for 1D electro-osmosis consolidation with preloading. Feldkamp and Belhomme [19] later derived a solution for large strain 1D electro-osmosis consolidation. Lewis and Garner [24] presented a twodimensional (2D) finite element solution for modelling the coupling effect of the electric and hydraulic gradients. Shang [42, 43] developed a 2D analytical model, combining the preloading and electro-osmosis consolidation of clay soils. Rittirong and Shang [39] presented a 2D finite difference model to analyse indirectly the subsurface settlement and undrained shear strength. However, none of the above models directly considered the mechanical behaviour of the soil, nor the full multi-physical coupling that occurs during the electro-osmosis consolidation process.

In most of the above approaches, the electro-osmosis consolidation is limited to the consideration of 1D problems. Moreover, force equilibrium and a linear elastic constitutive relationship for the soil are included implicitly in the formulation of the pore water transport, following Terzaghi's approach. As such, only two coupled/uncoupled partial differential equations for pore water transport and electrical current transport are solved, using either analytical approaches or numerical methods. In contrast, Yuan et al. [50] presented a fully coupled solution considering force equilibrium, pore water transport and electrical transport, assuming that hydraulic and electrical properties remain constant during the simulation. Tamagnini et al. [46] presented a numerical model for electro-osmosis processes in fine-grained soils, accounting for gas generation and transport under unsaturated conditions. Yuan and Hicks [49] presented an elastic electro-osmosis consolidation model for saturated soils experiencing large strains, and considered volumetric strains induced by changes in both the hydraulic- and electric-driven pore water flows. However, these approaches only incorporated an elastic constitutive relationship for the soil. In contrast, Yuan et al. [51] developed a numerical model for electro-osmosis consolidation at small strain, coupling displacement, pore water flow and electrical field, and incorporated the Modified Cam Clay model for modelling nonlinear material behaviour.

The main objective of this paper is to extend the theory of large strain elastic electro-osmosis consolidation to elasto-plasticity, by employing the Modified Cam Clay model to describe the elasto-plastic behaviour of clays. Moreover, some empirical expressions are incorporated to consider the nonlinear variation, with void ratio, of the hydraulic and electrical conductivities, and the electroosmosis permeability, of the soil mass, as these are considered to be more realistic than constant transport properties for describing the highly nonlinear processes. Three fully coupled governing equations, considering force equilibrium, pore water transport and electrical conduction, are presented, and solved via the finite element method in the space domain and an implicit integration scheme in the time domain. Since no suitable numerical solutions of simple problems are available for validation purposes, a numerical simulation is compared with Feldkamp and Belhomme's [19] experiment of large strain electroosmosis consolidation of a vertical column. Furthermore, other numerical examples of electro-osmosis consolidation are presented. The results of these analyses suggest that the differences between large and small strain models are noticeable and should not be neglected, and that considering the nonlinear variation of the soil properties, especially the elasto-plastic constitutive relationships, has a significant impact on the deformation characteristics and time-dependent evolution of the process. Finally, a welldocumented field application of electro-osmosis treatment reported by Bjerrum et al. [7] is simulated, for further verification of the numerical model.

The paper is organized as follows. In Sect. 2, the governing equations of electro-osmosis consolidation, as well as the background of large strain theory, are recalled. Section 3 addresses the constitutive laws for the stress tensor, hydraulic conductivity, electro-osmosis permeability and electrical conductivity. In Sect. 4, the discretization of the governing equations in space and time is briefly described. The equations in matrix form are solved by means of a Newton-Raphson type procedure, and the numerical algorithm has been implemented into a finite element code. In Sect. 5, several numerical examples are solved, which are used for validation of the code based on the outlined approach. These examples demonstrate the importance of proper numerical modelling of the nonlinear soil behaviour during electroosmosis consolidation.

\section{Theoretical background and governing equations}

\subsection{Modelling framework}

The governing equations for the equilibrium of force, hydraulic head and electric potential are derived based on the following assumptions: (1) an isotropic fully saturated soil with an incompressible pore liquid and soil particles; (2) the coupled conduction processes occur under isothermal conditions; (3) the effect of electrical-chemical reactions is negligible; (4) electrophoresis and streaming currents are negligible [18]; (5) the flow of fluid due to the electrical and hydraulic gradients may be superimposed to 
obtain the total flow [18]; (6) Darcy's law is valid; and (7) Ohm's law is valid.

The kinematics and deformations for large strain updated Lagrangian formulations are provided in detail in Yuan and Hicks [49] and therefore only summarized here. Consider an arbitrary reference configuration $\mathbf{X}$, which has position $\mathbf{x}$ at time $t$. The mapping function $\varphi$ relates the initial and current position vectors. Hence, for a typical time step, the updated configuration of the body may be written as

$\mathbf{x}=\varphi(\mathbf{X}, t)$

A fundamental measure of the deformation is given by the deformation gradient, defined as

$\mathbf{F}=\frac{\partial \varphi}{\partial \mathbf{X}}=\frac{\partial \mathbf{x}}{\partial \mathbf{X}}$

The change in volume between the reference and current configurations can be established as

$\mathrm{d} V=J \mathrm{~d} V_{0}$

where $V_{0}$ and $V$ are the reference and current volumes, respectively, and $J$ is the Jacobian determinant which is the determinant of the deformation gradient $\mathbf{F}$. The Green strain tensor is given as

$\mathbf{E}=\frac{1}{2}\left(\mathbf{F}^{\mathrm{T}} \mathbf{F}-\mathbf{I}\right)$

where $\mathbf{I}$ is a unit tensor. In order to compute the Cauchy stress $\boldsymbol{\sigma}$, the second Piola-Kirchhoff stress $\mathbf{S}$ measured at the reference configuration has to be computed first. The Cauchy stress is related to the second Piola-Kirchhoff (PK2) stress by the deformation gradient as follows:

$\boldsymbol{\sigma}=\frac{1}{J} \mathbf{F}^{\mathrm{T}} \mathbf{S F}$

The spatial velocity $\mathbf{v}$ of the material point $\mathbf{x}$ is given by

$\mathbf{v}=\mathbf{v}(\mathbf{x}, t)=\frac{\partial \mathbf{x}}{\partial t}$

For an arbitrary scalar valued function $f^{\pi}(\mathbf{x}, t)$, its material time derivative, relative to its spatial description and referring to a moving particle of the $\pi$ th phase, is defined by

$\frac{\mathrm{D}^{\pi} f^{\pi}}{\mathrm{D} t}=\frac{\partial f^{\pi}}{\partial t}+\nabla f^{\pi} \cdot \mathbf{v}^{\pi}$

In a multiphase porous medium, it is common to take the motion of the solid configuration as a reference and to describe the motion of, for example, the water (w) phase particles relative to those of the solid (s). Hence the water relative velocity can be written as

$\mathbf{v}^{\mathrm{ws}}=\mathbf{v}^{\mathrm{w}}-\mathbf{v}^{\mathrm{s}}$
By considering the above relative velocities, the material time derivative of $f^{\mathrm{w}}$ with respect to the moving solid phase is given by

$\frac{\mathrm{D}^{\mathrm{s}} f^{\mathrm{w}}}{\mathrm{D} t}=\frac{\mathrm{D}^{\mathrm{w}} f^{\mathrm{w}}}{\mathrm{D} t}+\nabla f^{\mathrm{w}} \cdot \mathbf{v}^{\mathrm{sw}}$

2.2 Mechanical equilibrium

The stress equilibrium equation can be expressed by

$\nabla \cdot \boldsymbol{\sigma}+\mathbf{b}=\mathbf{0}$

where $\boldsymbol{\sigma}$ represents the total Cauchy stress vector and $\mathbf{b}$ represents the body force vector. In an updated Lagrangian (UL) formulation, in order to solve the above equation, all quantities must be transferred to the current configuration. So the equilibrium equation, at time $t+\Delta t$, can be written in its weak form as

$$
\begin{aligned}
\int_{V^{t}} \mathbf{S}^{t+\Delta t} \cdot \delta \mathbf{E}^{t+\Delta t} \mathrm{~d} V^{t}= & \int_{V^{t}} \mathbf{b}^{t+\Delta t} \cdot \delta \mathbf{u}^{t+\Delta t} \mathrm{~d} V^{t} \\
& +\int_{S^{t}} \mathbf{t}^{t+\Delta t} \cdot \delta \mathbf{u}^{t+\Delta t} \mathrm{~d} S^{t}
\end{aligned}
$$

where $\mathbf{S}$ is the PK2 stress tensor, $\delta \mathbf{u}$ is the virtual displacement, $\mathbf{t}$ are the boundary traction components and $V$ is the volume of the body. Moreover, the incremental decomposition of the PK2 stress tensor can be expressed as

$\mathbf{S}^{t+\Delta t}=\mathbf{S}^{t}+\Delta \mathbf{S}$

when referenced to the current configuration at time $t$, for which $\mathbf{S}^{t}=\boldsymbol{\sigma}^{t}$ in the UL formulations. The decomposition of the Green strain tensor can be written as

$$
\begin{aligned}
\mathbf{E} & =\boldsymbol{\varepsilon}+\boldsymbol{\eta} \\
\boldsymbol{\varepsilon} & =-\frac{1}{2}\left(\nabla \mathbf{u}+(\nabla \mathbf{u})^{\mathrm{T}}\right) \\
\boldsymbol{\eta} & =-\frac{1}{2}\left((\nabla \mathbf{u})^{\mathrm{T}} \cdot \nabla \mathbf{u}\right)
\end{aligned}
$$

where $\boldsymbol{\varepsilon}$ and $\boldsymbol{\eta}$ are the linear and nonlinear parts of the Green strain tensor, respectively. By substituting Eqs. (12) and (13) into Eq. (11) and ignoring the high-order terms, the linearized governing equation for equilibrium is obtained as

$$
\begin{aligned}
\int_{V^{t}} \overline{\mathbf{D}} \cdot \mathrm{d} \boldsymbol{\varepsilon} \cdot \delta \boldsymbol{\varepsilon} \mathrm{d} V^{t}+\int_{V^{t}} \boldsymbol{\sigma}^{t} \cdot \delta \boldsymbol{\eta} \mathrm{d} V^{t} \\
\quad=\int_{V^{t}} \mathbf{b}^{t+\Delta t} \cdot \delta \mathbf{u d d} V^{t}+\int_{S^{t}} \mathbf{t}^{t+\Delta t} \cdot \delta \mathbf{u} \mathrm{d} S^{t}-\int_{V^{t}} \boldsymbol{\sigma}^{t} \cdot \delta \boldsymbol{\varepsilon} \mathrm{d} V^{t}
\end{aligned}
$$

where $\overline{\mathbf{D}}$ is the stress-strain matrix derived from the constitutive relationship $\mathrm{d} \mathbf{S}=\overline{\mathbf{D}} \cdot \mathrm{d} \mathbf{E}$ [34]. 


\subsection{Balance of water mass}

The mass balance law for the solid phase in the current configuration may be written as

$\frac{\mathrm{D}^{\mathrm{s}}(1-n) \rho^{\mathrm{s}}}{\mathrm{D} t}+(1-n) \rho^{\mathrm{s}} \nabla \cdot \mathbf{v}^{\mathrm{s}}=0$

where $n$ is the porosity and $\rho^{\mathrm{s}}$ is the density of the solid particles. By taking account of the incompressibility of the solid particles, the mass balance equation becomes

$-\frac{\mathrm{D}^{\mathrm{s}} n}{\mathrm{D} t}+(1-n) \nabla \cdot \mathbf{v}^{\mathrm{s}}=0$

The mass balance law for the water phase in the current configuration may be written as

$\frac{\mathrm{D}^{\mathrm{w}}\left(n \rho^{\mathrm{w}}\right)}{\mathrm{D} t}+n \rho^{\mathrm{w}} \nabla \cdot \mathbf{v}^{\mathrm{w}}=0$

By introducing the relative velocity from Eq. (8) and the material time derivative with respect to the moving solid from Eq. (9), the water mass balance equation becomes

$\frac{\mathrm{D}^{\mathrm{s}}\left(n \rho^{\mathrm{w}}\right)}{\mathrm{D} t}+\nabla \cdot\left(n \rho^{\mathrm{w}} \mathbf{v}^{\mathrm{ws}}\right)+n \rho^{\mathrm{w}} \nabla \cdot \mathbf{v}^{\mathrm{s}}=0$

By taking account of the incompressibility of the water, and by substituting Eq. (16) into Eq. (18), the material time derivative of $n$ vanishes, so that

$\nabla \cdot\left(\mathbf{v}^{\mathrm{s}}+\overline{\mathbf{v}}\right)=0$

where $\overline{\mathbf{v}}=n \mathbf{v}^{\mathrm{ws}}$ is the filtration velocity of the water relative to the soil skeleton.

\subsection{Balance of electric charge}

By applying the conservation of charge and assuming the current is steady state, the governing equation for the electric field can be represented as follows:

$-\nabla \cdot \mathbf{j}=C_{\mathrm{p}} \frac{\partial V}{\partial t}$

where $\mathbf{j}$ is the electrical current flux, $C_{\mathrm{p}}$ is the electrical capacitance per unit volume and $V$ is the electrical potential. As the electrical capacitance of the soil can be considered negligible, $C_{\mathrm{p}}=0$ is assumed in this paper.

\section{Constitutive equations}

The soil properties and electrical fields change during the electro-osmosis consolidation. The elasto-plastic soil behaviour causes nonlinear deformation of the soil. Moreover, the flow of water causes a non-uniform decrease in the water content and void ratio of the soil mass. These factors lead to changes in the hydraulic and electrical conductivities, and in the electro-osmosis permeability. Accordingly, the solution of the nonlinear coupled system can be solved numerically if suitable constitutive relationships are chosen.

\subsection{Solid skeleton}

The Cam Clay model was developed in the 1960s and is intended to capture the basic features of normally consolidated, as well as lightly over consolidated, clay [40, 41]. There are two well-known versions of this model. The first is the so-called original Cam Clay model, while the other is the Modified Cam Clay model. In this study, the Modified Cam Clay model is employed to simulate elasto-plastic soil behaviour during electro-osmosis consolidation. It employs an associated flow rule, and the yield $(f)$ and plastic potential $(g)$ functions can be expressed by

$f=g=q^{2}-M^{2} p^{\prime}\left(p_{\mathrm{c}}-p^{\prime}\right)$

where the stress invariants $p^{\prime}$ and $q$ represent the mean effective stress and deviatoric stress, respectively, $M$ is the slope of the critical state line (CSL) in the $p^{\prime}-q$ plane and $p_{\mathrm{c}}$ is the pre-consolidation pressure, which is the hardening parameter of the model that can be expressed by

$p_{\mathrm{c}}=p_{\mathrm{c} 0} \exp \left(\frac{\left(1+e_{0}\right) \Delta \varepsilon_{v}^{\mathrm{p}}}{\lambda-\kappa}\right)$

where $\lambda$ and $\kappa$ are the plastic compression index and unloading-reloading index, respectively, $e_{0}$ is the initial void ratio, $\Delta \varepsilon_{v}^{\mathrm{p}}$ is the increment of plastic volumetric strain and $p_{\mathrm{c} 0}$ is the pre-consolidation pressure at the beginning of plastic loading. According to standard elasto-plastic theory, $\mathbf{D}_{\mathrm{ep}}$ is the elasto-plastic stressstrain matrix given by

$$
\mathbf{D}_{\mathrm{ep}}=\mathbf{D}_{\mathrm{e}}-\frac{\mathbf{D}_{\mathrm{e}} \frac{\partial g}{\partial \boldsymbol{\sigma}^{\prime}} \frac{\partial f^{\mathrm{T}}}{\partial \boldsymbol{\sigma}^{\prime}} \mathbf{D}_{\mathrm{e}}}{H+\frac{\partial f}{\partial \boldsymbol{\sigma}^{\prime}} \mathbf{D}_{\mathrm{e}} \frac{\partial g}{\partial \boldsymbol{\sigma}^{\prime}}}
$$

where $\mathbf{D}_{\mathrm{e}}$ is the elastic stress-strain matrix and noting that, when the Jaumann stress rate is employed, $\mathbf{D}_{\text {ep }}$ has an identical form to that encountered in small strain theory. $\boldsymbol{\sigma}^{\prime}$ is the effective stress and $H$ is the modulus of plastic hardening/softening.

The coupling between the deformation and flow processes is established using the principle of effective stress. Hence the total stress can be written as

$\boldsymbol{\sigma}=\boldsymbol{\sigma}^{\prime}+\mathbf{I} p$

where $p$ is the pore water pressure. When assuming large strain kinematics, involving also large rotations, care must be taken to ensure the material frame invariance of the model. To do that, a frame-independent stress rate such as the Jaumann stress rate needs to be introduced, i.e. [35] 
$\mathrm{d} \boldsymbol{\sigma}^{\mathrm{J}}=\mathrm{d} \boldsymbol{\sigma}^{\prime}-\mathrm{d} \boldsymbol{\Omega} \cdot \boldsymbol{\sigma}^{\prime}-\boldsymbol{\sigma}^{\prime} \cdot \mathrm{d} \boldsymbol{\Omega}^{\mathrm{T}}=\mathbf{D}_{\mathrm{ep}} \cdot \mathrm{d} \boldsymbol{\varepsilon}$

where $\mathbf{D}_{\mathrm{ep}}$ is the stress-strain matrix derived from the constitutive relations in terms of the Cauchy stress and linear strain tensor $\mathrm{d} \boldsymbol{\varepsilon}$ [34], and the Jaumann stress rate is related to the Cauchy stress rate by the non-objective spin tensor $\boldsymbol{\Omega}$, given by

$\mathbf{\Omega}=\frac{1}{2}\left[(\nabla \mathbf{u})-(\nabla \mathbf{u})^{\mathrm{T}}\right]$

By substituting Eq. (25) into the effective stress equation, Eq. (24), the stress increment can be written as

$\mathrm{d} \boldsymbol{\sigma}=\mathbf{D}_{\text {ep }} \cdot \mathrm{d} \boldsymbol{\varepsilon}+\mathrm{d} \boldsymbol{\Omega} \cdot \boldsymbol{\sigma}^{\prime}+\boldsymbol{\sigma}^{\prime} \cdot \mathrm{d} \boldsymbol{\Omega}^{\mathrm{T}}+\mathbf{I} \mathrm{d} p$

In the large strain formulation based on the Jaumann stress rate, Eq. (25), the effective stress increment can be calculated by

$\boldsymbol{\sigma}^{\prime t+\Delta t}=\boldsymbol{\sigma}^{\prime t}+\int_{0}^{\Delta \varepsilon} \mathbf{D}_{\mathrm{ep}} \cdot \mathrm{d} \boldsymbol{\varepsilon}+\int_{0}^{\Delta \boldsymbol{\Omega}}\left(\mathrm{d} \boldsymbol{\Omega} \cdot \boldsymbol{\sigma}^{\prime t}+\boldsymbol{\sigma}^{\prime t} \cdot \mathrm{d} \mathbf{\Omega}^{\mathrm{T}}\right)$

Stress integration algorithms for large strain analysis have been discussed many times before [16, 17, 34]. It has been shown that stress transformation due to rigid body rotation can be included in the equations before, after or during the stress integration in each increment [36]. It has also been shown that, with this method, stress integration schemes used for small strain can be easily extended to large strain [34]. An explicit stress integration scheme with automatic substepping and error control for large strain is implemented here to solve the elasto-plastic constitutive relationship.

\subsection{Pore water transport}

The constitutive equation for the pore water flow velocity in electro-osmosis comprises two components. One is the hydraulic flow caused by the gradients of pore water pressure and the other is the electro-osmosis flow caused by electrical potential gradients. From Darcy's law, the hydraulic flow can be expressed as

$\mathbf{v}_{\mathrm{w}}=-\frac{k_{\mathrm{w}}}{\gamma_{\mathrm{w}}}\left(\nabla p+\gamma_{\mathrm{w}} z\right)$

where $k_{\mathrm{w}}, \gamma_{\mathrm{w}}$ and $z$ are the coefficient of hydraulic conductivity, unit weight of water and elevation, respectively. The fluid flux due to electro-osmosis can be expressed as a linear function of the applied electrical potential gradient:

$\mathbf{v}_{\mathrm{eo}}=-k_{\mathrm{eo}} \nabla V$

where $k_{\text {eo }}$ is the coefficient of electro-osmosis permeability. According to Esrig's [18] assumption, these two independent flows can be combined to give the total flow: $\overline{\mathbf{v}}=\mathbf{v}_{\mathrm{w}}+\mathbf{v}_{\mathrm{eo}}=-\frac{k_{\mathrm{w}}}{\gamma_{\mathrm{w}}}\left(\nabla p+\gamma_{\mathrm{w}} z\right)-k_{\mathrm{eo}} \nabla V$

The Helmholtz-Smoluchowski model is widely used for explaining the electro-osmosis phenomenon in soil [31]. In this model, $k_{\mathrm{eo}}$ is derived from the balance between the electrical force causing the water flow and the frictional force between the water and the wall of the capillary. It can be written as

$k_{\mathrm{eo}}=-\frac{\zeta \varepsilon n}{\mu}$

where $\zeta$ is the zeta potential, $\varepsilon$ is the permittivity of the pore fluid and $\mu$ is the viscosity of the pore fluid. In clayey soils, since the permittivity and viscosity of the pore water are approximately constant over a fairly large range of salinity, $k_{\text {eo }}$ is controlled primarily by the zeta potential and soil porosity. As reported by Mohamedelhassan and Shang [33], $k_{\text {eo }}$ is mainly controlled by porosity when the pore fluid salinities are smaller than a certain value $(8 \mathrm{~g} \mathrm{NaCl} / \mathrm{l}$ in their paper), and increases in magnitude with increase in the soil porosity. There is a linear relationship between the electro-osmosis permeability and porosity, which can be expressed as

$k_{\mathrm{eo}}=A n+B$

where $A$ and $B$ are material constants that can be determined experimentally.

The hydraulic conductivity is one of the crucial parameters in the electro-osmosis process, and it greatly influences the rate of consolidation and negative pore water pressure development. Although, in most electro-osmosis theories, the coefficient of hydraulic conductivity is assumed to be constant, in reality it is a function of the porosity or void ratio. A relationship between hydraulic conductivity and void ratio, $e$, has been reported by many researchers [31, 33]. Such a relationship is typically obtained by curve-fitting experimental data and depends on the type of soil. For clays, a logarithmic equation may be used:

$\log k_{\mathrm{w}}=C e+D$

where $C$ and $D$ are material constants.

\subsection{Electric charge transport}

According to Ohm's law, the electrical current flow can be expressed by

$\mathbf{j}=-k_{\sigma \mathrm{e}} \nabla V$

where $k_{\sigma \mathrm{e}}$ is the electrical conductivity of the soil. The electrical conductivity is a function of the soil mineralogy and pore fluid composition. However, it is evident from experiments that the electrical conductivity of the pore 
water is greater than that of the bulk soil. The electrical conductivity of a saturated porous medium can be represented by the following model [33]:

$k_{\sigma \mathrm{e}}=\frac{k_{\sigma \mathrm{s}} k_{\sigma \mathrm{w}}(1+e)}{k_{\sigma \mathrm{w}}+e k_{\sigma \mathrm{s}}}$

where $k_{\sigma \mathrm{s}}$ is the surface conductivity of the clay particles and $k_{\sigma \mathrm{w}}$ is the conductivity of the pore water. When the pore fluid concentration is relatively low, surface conductivity plays the major role in controlling the electrical conductivity of the clay [26]. Mohamedelhassan and Shang [33] found that soil surface conductivity is proportional to the pore fluid salinity and soil void ratio.

\subsection{Void ratio and conductivity/permeability updates}

The nonlinear relationship between conductivity or permeability and void ratio has been accounted for in the above formulation. However, the method for updating the void ratio or porosity needs to be introduced here. First, let $e^{t}$ represent the void ratio at time $t$. As the volume changes during soil deformation, the relationship for the incremental void ratio at time $t+\Delta t$ may be given by

$e^{t+\Delta t}=J\left(1+e^{t}\right)-1$

where $J$ is the Jacobian of the deformation gradient tensor. In an updated Lagrangian approach where time step increments $\Delta t$ are assumed to be small enough to justify neglecting the contribution from the second-order strain components during each step, the volume strain increment may be approximated by the trace of the linear strain tensor, so that $J \approx 1+$ tre. The void ratio, which is updated and stored at each integration point, can then be expressed as [25, 29]

$e^{t+\Delta t}=(1+\operatorname{tr} \boldsymbol{\varepsilon})\left(1+e^{t}\right)-1=e^{t}+\left(1+e^{t}\right) \operatorname{tr} \varepsilon$

Note that, when dealing with large deformation and rotation, some care needs to be taken regarding changes in the conductivity and permeability tensors due to rigid body rotation, if the material is initially anisotropic. This effect is expressed as

$\mathbf{k}_{\pi}^{t+\Delta t}=\mathbf{R}^{\mathrm{T}} \cdot \mathbf{k}_{\pi}^{t} \cdot \mathbf{R}$

where $\mathbf{k}_{\pi}$ represents the conductivity or permeability matrices of the hydraulic, electro-osmosis and electrical components, and $\mathbf{R}$ is the local rotation matrix which corresponds to the appropriate rotations of the coordinate axes $[9,25,35]$.

\subsection{Final governing equations}

By taking account of the constitutive equations, Eqs. (27), (31) and (35), the primary variables, namely the displacements, pore pressure and electrical potential, are coupled through the governing equations at large strain. The mechanical equilibrium, mass balance of water and mass balance of electric charge, i.e. Eqs. (10), (19) and (20) can then be recast in weak form as follows:

$$
\begin{aligned}
& \int_{V^{t}} \mathbf{D}_{\mathrm{ep}} \cdot \mathrm{d} \boldsymbol{\varepsilon} \cdot \delta \boldsymbol{\varepsilon} \mathrm{d} V^{t}+\int_{V^{t}}\left(\mathrm{~d} \boldsymbol{\Omega} \cdot \boldsymbol{\sigma}^{\prime t}+\boldsymbol{\sigma}^{\prime t} \cdot \mathrm{d} \mathbf{\Omega}^{\mathrm{T}}\right) \cdot \delta \boldsymbol{\varepsilon} \mathrm{d} V^{t} \\
& +\int_{V^{t}} \mathbf{I} \mathrm{d} p \delta \boldsymbol{\varepsilon} \mathrm{d} V^{t}+\int_{V^{t}} \boldsymbol{\sigma}^{t} \cdot \delta \boldsymbol{\eta} \mathrm{d} V^{t}=\int_{V^{t}} \mathbf{b}^{t+\Delta t} \cdot \delta \mathbf{u} \mathrm{d} V^{t} \\
& \quad+\int_{S^{t}} \mathbf{t}^{t+\Delta t} \cdot \delta \mathbf{u} \mathrm{d} S^{t}-\int_{V^{t}} \boldsymbol{\sigma}^{t} \cdot \delta \boldsymbol{\varepsilon} \mathrm{d} V^{t} \\
& \int_{V^{t}} \nabla \cdot \mathbf{v}^{\mathrm{s}} \delta p \mathrm{~d} V^{t}+\int_{V^{t}}\left(\frac{k_{\mathrm{w}}}{\gamma_{\mathrm{w}}}\left(\nabla p+\gamma_{\mathrm{w}} z\right)+k_{\mathrm{eo}} \nabla V\right) \cdot \nabla \delta p \mathrm{~d} V^{t}=0 \\
& \int_{V^{t}}\left(k_{\sigma \mathrm{e}} \nabla V\right) \cdot(\nabla \delta V) \mathrm{d} V^{t}=0
\end{aligned}
$$

where $\delta \mathbf{u}, \delta p$ and $\delta V$ are the virtual displacements, virtual pore water pressure and virtual electric potential, respectively.

\section{Finite element implementation}

\subsection{Spatial discretization}

The finite element method [25, 45] has been used to solve the coupled system of equations, Eq. (40), i.e. as functions of the respective element nodal value vectors $\mathbf{u}_{\mathrm{e}}, \mathbf{p}_{\mathrm{e}}$ and $\mathbf{V}_{\mathrm{e}}$. Hence the unknown dependent variables are discretized over the whole domain using the element shape function matrices $\mathbf{N}_{\mathbf{u}}, \mathbf{N}_{p}$ and $\mathbf{N}_{V}$ :

$$
\begin{aligned}
\mathbf{u} & =\mathbf{N}_{\mathbf{u}} \mathbf{u}_{\mathrm{e}} \\
p & =\mathbf{N}_{p} \mathbf{p}_{\mathrm{e}} \\
V & =\mathbf{N}_{V} \mathbf{V}_{\mathrm{e}}
\end{aligned}
$$

where $\mathbf{u}, p$ and $V$ are the respective dependent variables of displacement, excess pore pressure and electrical potential.

The Galerkin procedure is used to obtain the weak form of the governing equations. Hence the following system of fully coupled equations is derived in matrix form:

$$
\begin{aligned}
& {\left[\mathbf{K}_{\mathrm{ep}}+\mathbf{K}_{\mathrm{g}}\right] \dot{\mathbf{u}}+\mathbf{L} \dot{\mathbf{p}}=\dot{\mathbf{F}}^{\text {ext }}} \\
& \mathbf{L}^{\mathrm{T}} \dot{\mathbf{u}}+\mathbf{K}_{\mathrm{c}} \mathbf{p}+\mathbf{K}_{\mathrm{eo}} \mathbf{V}=\mathbf{Q}_{p}^{\mathrm{ext}} \\
& \mathbf{K}_{\sigma \mathrm{e}} \dot{\mathbf{V}}=\dot{\mathbf{Q}}_{V}^{\mathrm{ext}}
\end{aligned}
$$

where the definitions of the coefficient matrices and the load and flow vectors are given in "Appendix". 


\subsection{Time stepping and solution procedure}

The governing equations of the coupled system, Eq. (42), can be written as

$\mathbf{C} \dot{\mathbf{X}}+\mathbf{K X}=\dot{\mathbf{W}}^{\text {ext }}$

where

$$
\begin{gathered}
\mathbf{C}=\left[\begin{array}{ccc}
\mathbf{K}_{\mathrm{nl}} & \mathbf{L} & \mathbf{0} \\
\mathbf{L}^{\mathrm{T}} & \mathbf{0} & \mathbf{0} \\
\mathbf{0} & \mathbf{0} & \mathbf{K}_{\sigma \mathrm{e}}
\end{array}\right], \mathbf{K}=\left[\begin{array}{ccc}
\mathbf{0} & \mathbf{0} & \mathbf{0} \\
\mathbf{0} & \mathbf{K}_{\mathrm{c}} & \mathbf{K}_{\mathrm{eo}} \\
\mathbf{0} & \mathbf{0} & \mathbf{0}
\end{array}\right], \\
\mathbf{X}=\left\{\begin{array}{c}
\mathbf{u} \\
\mathbf{p} \\
\mathbf{V}
\end{array}\right\}, \dot{\mathbf{X}}=\left\{\begin{array}{c}
\dot{\mathbf{u}} \\
\dot{\mathbf{p}} \\
\dot{\mathbf{V}}
\end{array}\right\}, \dot{\mathbf{W}}^{\mathrm{ext}}=\left\{\begin{array}{l}
\dot{\mathbf{F}}^{\mathrm{ext}} \\
\mathbf{Q}_{p}^{\mathrm{ext}} \\
\dot{\mathbf{Q}}_{V}^{\mathrm{ext}}
\end{array}\right\}
\end{gathered}
$$

in which $\mathbf{K}_{\mathrm{nl}}=\left[\mathbf{K}_{\mathrm{ep}}+\mathbf{K}_{\mathrm{g}}\right]$.

A finite difference time stepping scheme is employed to solve Eq. (43). Applying the commonly used theta-method gives $[25,44]$

$$
\begin{aligned}
\mathbf{C} & \left\{\mathbf{X}_{n}-\mathbf{X}_{n-1}\right\}+\Delta t \mathbf{K}\left\{(1-\theta) \mathbf{X}_{n-1}+\theta \mathbf{X}_{n}\right\} \\
& =\Delta t\left\{\theta \dot{\mathbf{W}}_{n}^{\mathrm{ext}}+(1-\theta) \dot{\mathbf{W}}_{n-1}^{\mathrm{ext}}\right\}
\end{aligned}
$$

where $\theta$ is an integration parameter in the range $0 \leq \theta \leq 1$ and $\theta \geq 0.5$ for unconditional stability, and $\Delta t$ is the time step size. If $\theta=1.0$, the method gives the classical backward Euler scheme:

$\mathbf{C}\left\{\mathbf{X}_{n}-\mathbf{X}_{n-1}\right\}+\Delta t \mathbf{K} \mathbf{X}_{n}=\Delta t \dot{\mathbf{W}}_{n}^{\mathrm{ext}}$

Due to the material and geometric nonlinearity, this equation must be solved by iteration. Using the NewtonRaphson method, the residual vector of the coupled system is defined as

$\mathbf{R}\left(\mathbf{X}_{n}\right)=\Delta t \dot{\mathbf{W}}_{n}^{\mathrm{ext}}-\mathbf{C}\left\{\mathbf{X}_{n}-\mathbf{X}_{n-1}\right\}-\Delta t \mathbf{K} \mathbf{X}_{n}$

The iterative updating scheme is then

$$
\begin{aligned}
\delta \mathbf{X}^{j} & =\left(\mathbf{C}\left(\mathbf{X}_{n}^{j-1}\right)+\Delta t \mathbf{K}\left(\mathbf{X}_{n}^{j-1}\right)\right)^{-1} \mathbf{R}_{n}\left(\mathbf{X}_{n}^{j-1}\right) \\
\Delta \mathbf{X}_{n}^{j} & =\Delta \mathbf{X}_{n}^{j-1}+\delta \mathbf{X}^{j} \\
\mathbf{X}_{n}^{j} & =\mathbf{X}_{n-1}+\Delta \mathbf{X}_{n}^{j}
\end{aligned}
$$

where superscript $j$ indicates the iteration number. During the iteration process within each time step, the displacements, pore pressure and electric potential are continuously updated, with the iterations terminating once the unbalanced forces are small enough. Moreover, due to the nonlinear geometric stiffness matrix $\mathbf{K}_{\mathrm{g}}$ and global conductivity matrix $\mathbf{K}$, the overall matrix system to be solved is non-symmetric, so that a non-symmetric matrix solver must be employed.

\section{Numerical simulations}

In this section, the proposed formulation is validated and tested in the analysis of several numerical examples. Firstly, the proposed large strain model is validated against experimental data. As mentioned previously, no suitable numerical solutions exist for the problem of large strain electro-osmosis consolidation, and few analytical solutions and documented experiments have been developed or performed. However, one example is the 1D electroosmosis consolidation cell test reported by Feldkamp and Belhomme [19]. The experimental cell contained a colloidal silica column that was subjected to large strain electro-osmosis consolidation. The numerical results of an elasto-plastic simulation at large strain, with evolving hydraulic conductivity and electro-osmosis permeability, are here validated through comparison with the experimental results.

In a second numerical test, another large strain 1D model is investigated. This example highlights the difference between small and large strain analyses of elastic electro-osmosis consolidation. Then, in a third numerical test, the elasto-plastic behaviour of a 2D plane strain model employing the Modified Cam Clay constitutive model, as well as void ratio-dependent hydraulic conductivity, electro-osmosis permeability and electrical conductivity, is investigated for a large strain electro-osmosis consolidation problem. The results illustrate the importance of the elastoplastic formulation and void ratio-dependent electrical conductivity in the simulation of electro-osmosis consolidation. Finally, a field test of electro-osmosis treatment is simulated for further verification; this example demonstrates that the current intermittence and current reversal which were used during the field test can be simulated by the proposed approach.

In all examples, an eight-node quadrilateral finite element is adopted for displacements, and this is coupled to a four node quadrilateral element for modelling excess pore water pressure and electrical potential. The flow due to gravity is neglected in the first three examples, since the problem size is small in each case.

\subsection{Electro-osmosis test on a colloidal silica column}

Feldkamp and Belhomme's [19] experiment comprised a column of Plexiglas, $30.5 \mathrm{~cm}$ in length and of $7.5 \mathrm{~cm}$ internal diameter, packed with colloidal silica. Figure 1 shows a cross section through the silica specimen, as well as the assumed boundary conditions used for the present analysis. Displacements are prevented at the bottom of the sample, the left and right boundaries are restrained only in 


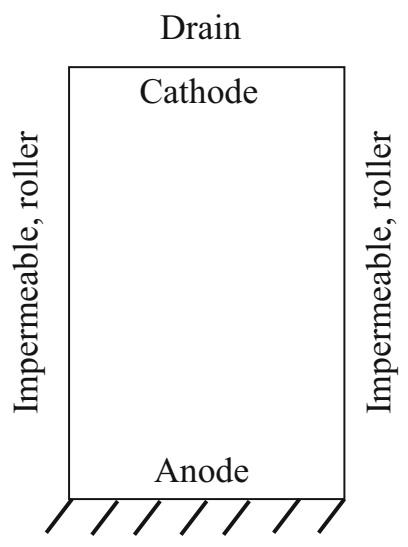

Fixed, impermeable

Fig. 1 1D electro-osmosis consolidation model (not to scale)

the horizontal direction, and the top of the sample is free. The hydraulic boundary conditions are free drainage at the top surface, whereas the remaining boundaries are impermeable. The cathode is the top boundary, the anode is the bottom boundary, and the left and right boundaries are impermeable with respect to electrical potential. As in the experiment, the electric current is fixed at $0.104 \mathrm{~A}$ (corresponding to a current density of $23.5 \mathrm{~A} / \mathrm{m}^{2}$ ), although it was reported that the applied voltage dropped from around 44 to $39.5 \mathrm{~V}$ during the experiment which lasted approximately $50 \mathrm{~min}$. From the known current and initial voltage, the initial electrical conductivity is calculated to be $0.163 \mathrm{~S} / \mathrm{m}$. Also, as in the experiment, a back pressure of $179 \mathrm{kPa}$ is applied throughout the test to avoid possible cavitation issues during negative pore pressure development.

With regard to the material properties, the hydraulic conductivity and electro-osmosis permeability of the colloidal silica were reported to be [19]:

$$
\begin{aligned}
& k_{\mathrm{w}}=1.4 \times 10^{-11} \frac{e^{2.54}}{1+e}(\mathrm{~m} / \mathrm{s}) \\
& k_{\mathrm{eo}}=3.0 \times 10^{-8}\left(\frac{1+e}{15.89}\right)^{1.36}\left(\mathrm{~m}^{2} / \mathrm{V} \mathrm{s}\right)
\end{aligned}
$$

in which $e=15.0$ at the start of the test. Feldkamp and Belhomme [19] obtained the relationship for $k_{\mathrm{w}}$ through direct experimentation, whereas the relationship for $k_{\text {eo }}$ was derived by curve-fitting against the experimental results. The Modified Cam Clay model is used here to describe the constitutive relationship, and the following parameters are used: plastic compression index, $\lambda=3.87$, which has been back-calculated from the test results; unloading-reloading index, $\quad \kappa=\lambda / 5=0.774$; friction constant, $M=0.772$, which corresponds to an assumed friction angle of $20^{\circ}$; and Poisson's ratio, $v=0.3$.

The computed development of negative excess pore pressure at the anode, during electro-osmosis consolidation,

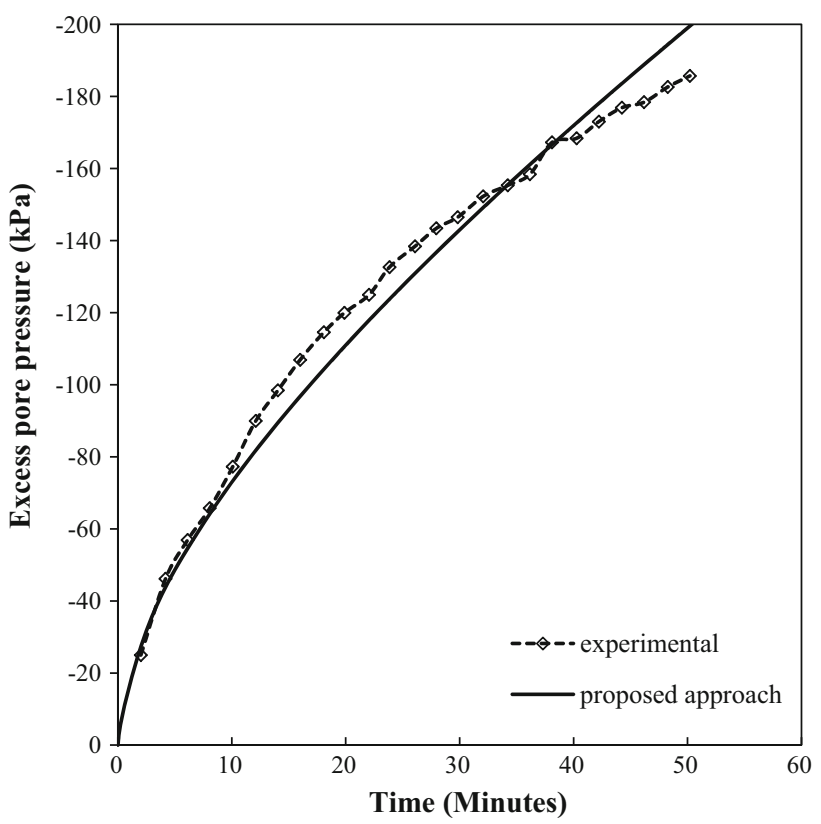

Fig. 2 Numerical results and experimental measurements of excess pore pressure at the anode versus time

is compared with the experimental results of Feldkamp and Belhomme [19] in Fig. 2. There is excellent agreement, indicating that the proposed numerical model is correctly modelling the coupled problem.

\subsection{One-dimensional electro-osmosis consolidation}

The second example involves the $1 \mathrm{D}$ elastic consolidation of a vertical soil column due to an applied electrical potential at the bottom boundary. This is presented to further verify the proposed numerical model, by comparing the simulation results with small strain results. The soil column is $1 \mathrm{~m}$ high and is subjected to an electrical potential of $10 \mathrm{~V}$ at the anode. The boundary conditions are the same as for the first example (Fig. 1). The material parameters used for the large strain and small strain models are listed in Table 1 and are based on the initial conditions for Mohamedelhassan and Shang's [33] tests.

Figure 3 shows the average degree of consolidation versus the time factor, defined by $T_{v}=k_{\mathrm{w}} \cdot t /\left(\gamma_{\mathrm{w}} \cdot m_{v} \cdot L^{2}\right)$, in which $m_{v}$ is the coefficient of compressibility and $L$ is the drainage path length. The large strain model predicts a faster rate of consolidation than the small strain model, partly due to it considering the geometric stiffness matrix which makes the stiffness strain dependent, but mainly because geometry changes are taken into account so that the drainage path length reduces with time (i.e. in contrast to the small strain model in which it remains constant).

The excess pore pressure distributions with depth (where the deformed mesh has been normalized against the 
Table 1 Material parameters used in second example (based on [33])

\begin{tabular}{lll}
\hline Property & Variable & Value \\
\hline Initial void ratio & $e$ & 3.95 \\
Young's modulus & $E$ & $2.0 \times 10^{5} \mathrm{~Pa}$ \\
Poisson's ratio & $v$ & 0.3 \\
Hydraulic conductivity & $k_{\mathrm{w}}$ & $1.72 \times 10^{-8} \mathrm{~m} / \mathrm{s}$ \\
Electro-osmosis permeability & $k_{\mathrm{eo}}$ & $1.47 \times 10^{-8} \mathrm{~m}^{2} /(\mathrm{V} \mathrm{s})$ \\
Electric conductivity & $k_{\sigma \mathrm{e}}$ & $0.802 \mathrm{~S} / \mathrm{m}$ \\
\hline
\end{tabular}

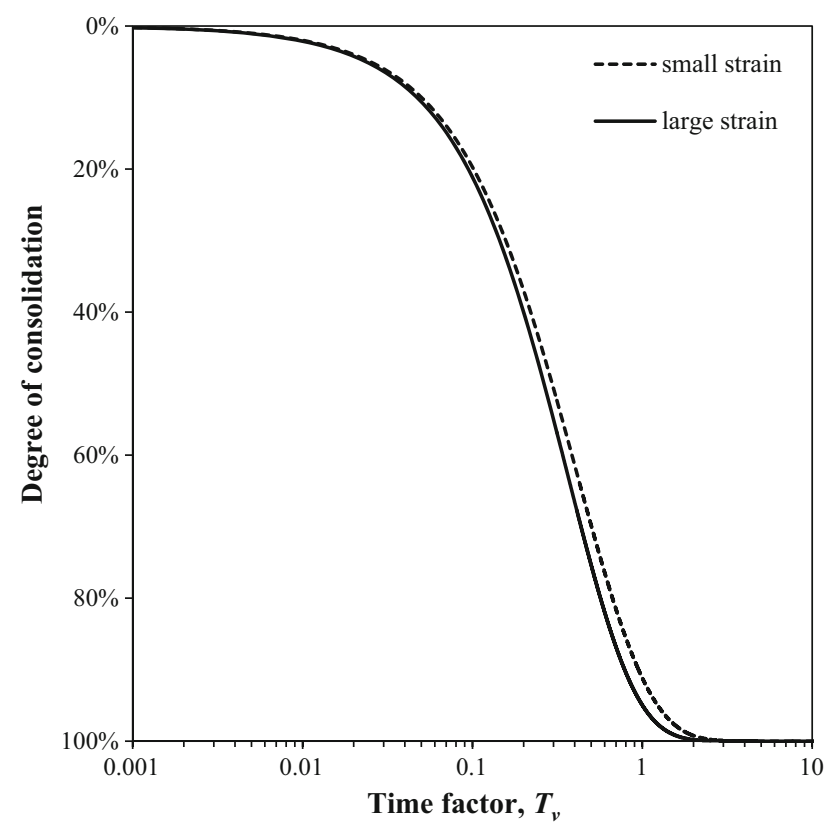

Fig. 3 Average degree of consolidation versus time factor for 1D consolidation by electro-osmosis

current column height), for various time factors, are presented in Fig. 4. The large strain model predicts a faster development of the excess pore water pressure than the small strain model. This is due to both the strain-dependent stiffness of the large strain model and the geometry change accounted for in the large strain model that makes the electrical gradient greater than that in the small strain model (in which the geometry is constant). As can be seen in Fig. 4, although the pore pressure distributions for both models are similar near the start of the consolidation (i.e. $\left.T_{v}=0.05\right)$, as the consolidation progresses the large strain results deviate from the small strain model (i.e. $T_{v}=0.2$, 0.6). However, both models predict the same excess pore pressure profile at the steady state, since, as explained by Yuan and Hicks [49], the final excess pore pressure is controlled only by the voltage applied if the hydraulic conductivity and electro-osmosis permeability remain constant. Moreover, because of this, both models predict

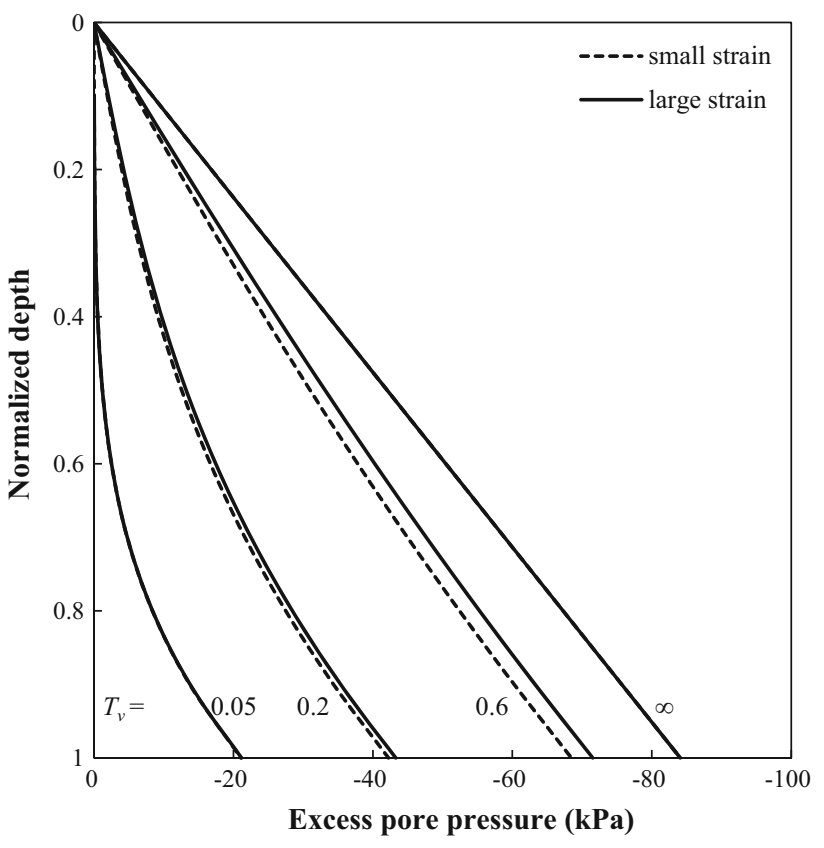

Fig. 4 Excess pore pressure versus normalized depth for various time factors

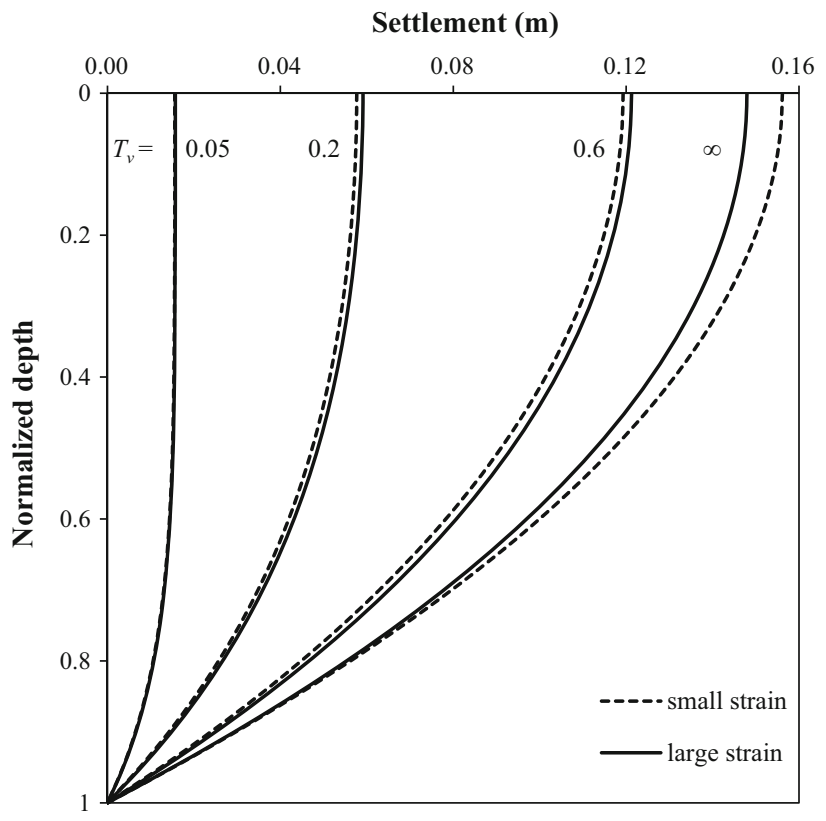

Fig. 5 Settlement versus normalized depth for various time factors

a linear final pore pressure distribution between the electrodes.

The settlements show similar changes with time factor to the excess pore pressure, due to the coupling of the pore water and soil skeleton; that is, the decrease in pore pressure coincides with an increase in effective stress and so to an increase in soil deformation. As shown in Fig. 5, the large strain model gives smaller final settlements than the 


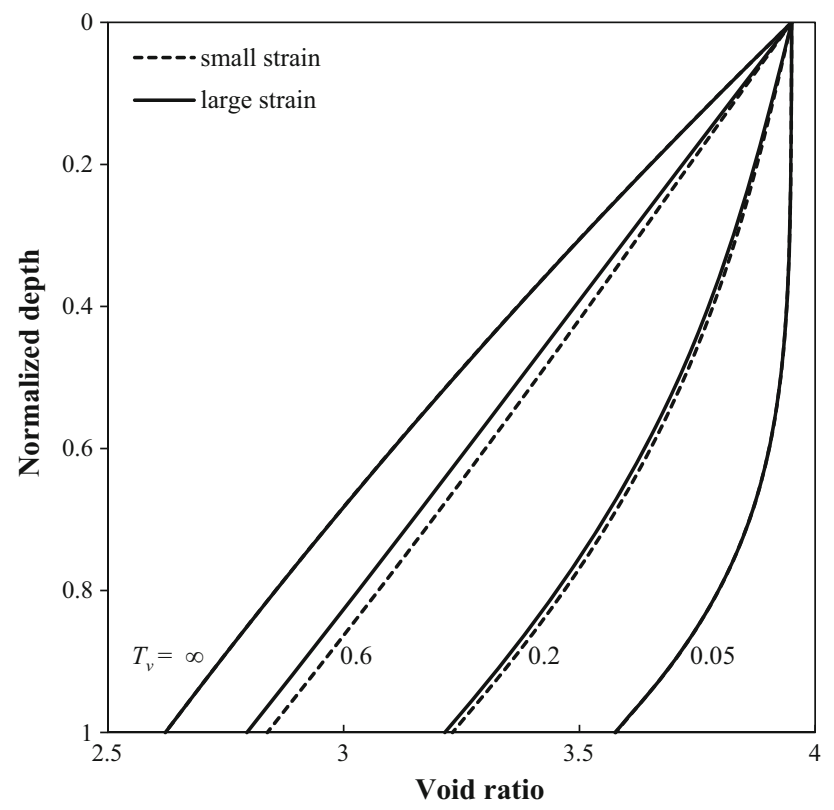

Fig. 6 Void ratio versus normalized depth for various time factors

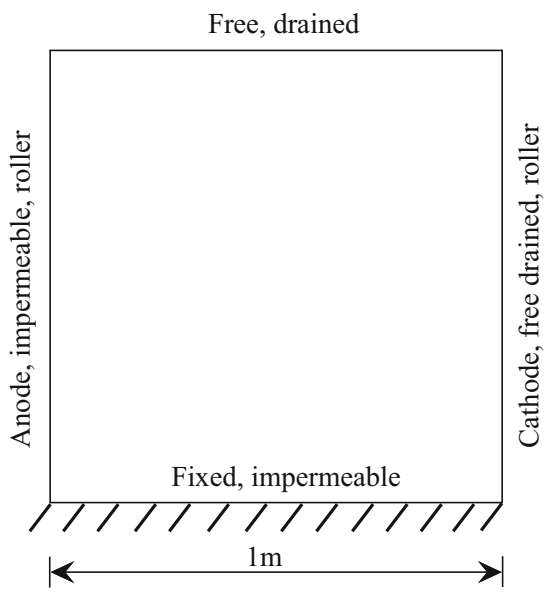

Fig. 7 2D electro-osmosis consolidation model

small strain model, because the large strain model takes account of the geometry-dependent nonlinear stiffness as reported by Yuan and Hicks [49].

The changes in void ratio result from the increase in effective stress in the soil sample. Figure 6 shows that the void ratio decrease occurs mainly near the anode, as this is where the largest negative pore pressures develop. Notice that the final void ratios are the same in both models, due to the final pore pressure profiles being the same for the two models.

\subsection{Two-dimensional elasto-plastic electro-osmosis consolidation}

A square domain of side length $1 \mathrm{~m}$ is presented in Fig. 7 and is used here to investigate elasto-plastic clay behaviour during electro-osmosis consolidation. The boundary conditions are as follows: the left edge is impermeable and on rollers allowing only vertical movement; the right edge is free draining and on rollers allowing only vertical movement; the bottom boundary is impermeable and fixed; and the top surface is free draining. In terms of electric boundary conditions: the anode is along the left edge, the right edge is the cathode and the horizontal boundaries are impermeable to electric current. An electric potential of $5 \mathrm{~V}$ is applied at the anode. The material parameters are selected from laboratory tests on the electro-osmosis of a marine sediment, carried out by Mohamedelhassan and Shang [33], including the following empirical expressions:

$$
\begin{aligned}
\log k_{\mathrm{w}} & =1.1075 e-11.297 \\
k_{\mathrm{eo}} & =3.27 \times 10^{-8} n-1.14 \times 10^{-8} \\
k_{\sigma \mathrm{e}} & =\frac{0.42(1+e)}{1.29+0.33 e}
\end{aligned}
$$

The material parameters for the Modified Cam Clay model are listed in Table 2 and are also derived from Mohamedelhassan and Shang's [33] laboratory tests. The initial effective stresses have been assigned using the effective unit weight of the soil and the coefficient of earth pressure at rest. However, to avoid potential numerical problems at very low stresses, a minimum effective stress of $1 \mathrm{kPa}$ is assumed. The initial yield surface location is then determined according to the effective pressure and assumed over-consolidation ratio (OCR). Finally, the electric potential is applied at the anode, and the displacements and pore water pressure changes due to the consolidation processes are computed.

The excess pore pressure versus time relationship at the base of the anode is shown in Fig. 8. (Note that the current model formulation does not set a limit on the tensile pore pressures generated; for example, to account for the effects of cavitation). The development of negative pore pressure changes results in an increase in the effective stress, which causes a decrease in the void ratio. Theoretically, the magnitude of the electro-osmosis consolidation is governed by the ratio of the electro-osmosis permeability and hydraulic conductivity $\left(k_{\mathrm{eo}} / k_{\mathrm{w}}\right)$ of the soil, it being greater for larger values of $k_{\mathrm{eo}} / k_{\mathrm{w}}$. Normally, the decrease of hydraulic conductivity is much faster than the decrease of electro-osmosis permeability with void ratio. Therefore, the ratio $k_{\mathrm{eo}} / k_{\mathrm{w}}$ increases with the decrease in void ratio, so that larger excess pore pressures develop (albeit more slowly) than for a constant $k_{\mathrm{eo}} / k_{\mathrm{w}}$.

Figure 9 illustrates the evolution of settlement at the top of the anode. It shows that large settlements are observed, even though the equilibrium state has not been reached after 60 days, demonstrating that large deformation theory is necessary for electro-osmosis consolidation. Figure 10 
Table 2 Material parameters for the Modified Cam Clay model (based on [33])

\begin{tabular}{lll}
\hline Void ratio at $p^{\prime}=1 \mathrm{kPa}$ & $e$ & 3.95 \\
Poisson's ratio & $v$ & 0.3 \\
Plastic compression index & $\lambda$ & 0.547 \\
Unloading-reloading index & $\kappa$ & 0.064 \\
Critical stress ratio & $M$ & 1.172 \\
Over-consolidation ratio & OCR & 1.0 \\
Coefficient of earth pressure at rest & $K_{0}$ & 1.0 \\
Total unit weight of soil & $\gamma$ & $14 \mathrm{kN} / \mathrm{m}^{3}$ \\
\hline
\end{tabular}

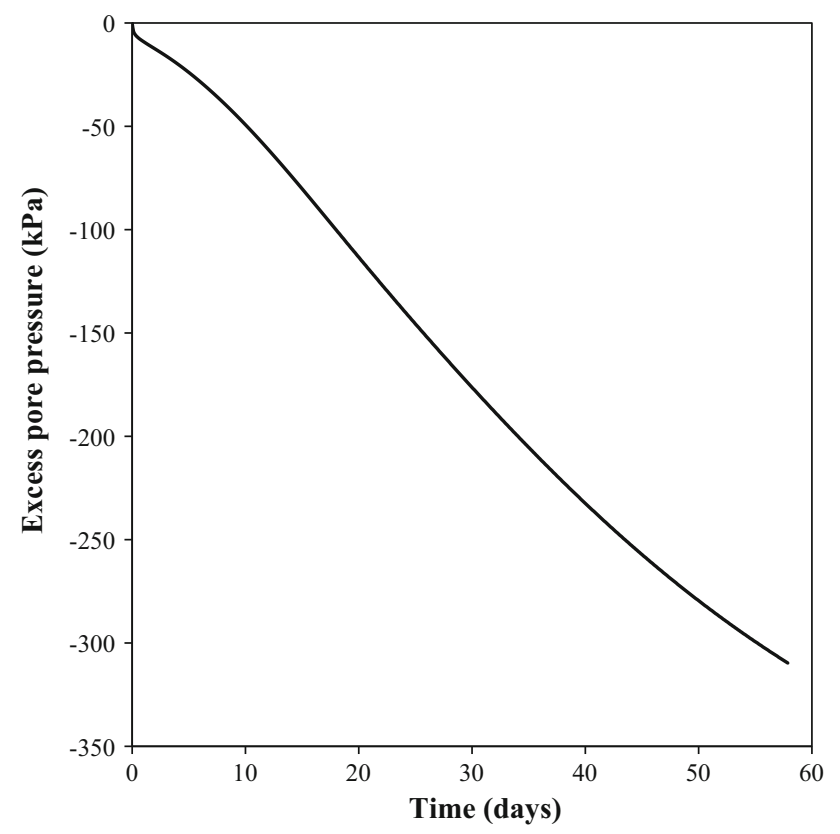

Fig. 8 Excess pore pressure versus time at the base of the anode

shows the settlement profiles of the top surface for different times. The settlements are mainly developed near the anode and, as the time increases, the difference in settlement between the locations of the two electrodes becomes larger. As already mentioned, the deformation is controlled by the excess pore pressure due to the coupling behaviour between the pore water and soil skeleton, and the largest negative excess pore pressures are developed near the anode. Similarly, Fig. 11 shows that the void ratio decrease mainly occurs near the anode. In contrast, the void ratio decrease near the cathode is negligible. Note that the initial void ratio is larger at the top of the domain than at the middle and bottom, and that the final void ratios at the middle and bottom of the layer near the anode are almost the same. This is because the region with the maximum negative excess pore pressure extends from the bottom to the middle of the soil domain, in the region near the anode, which means that the effective stresses are almost the same in that region.

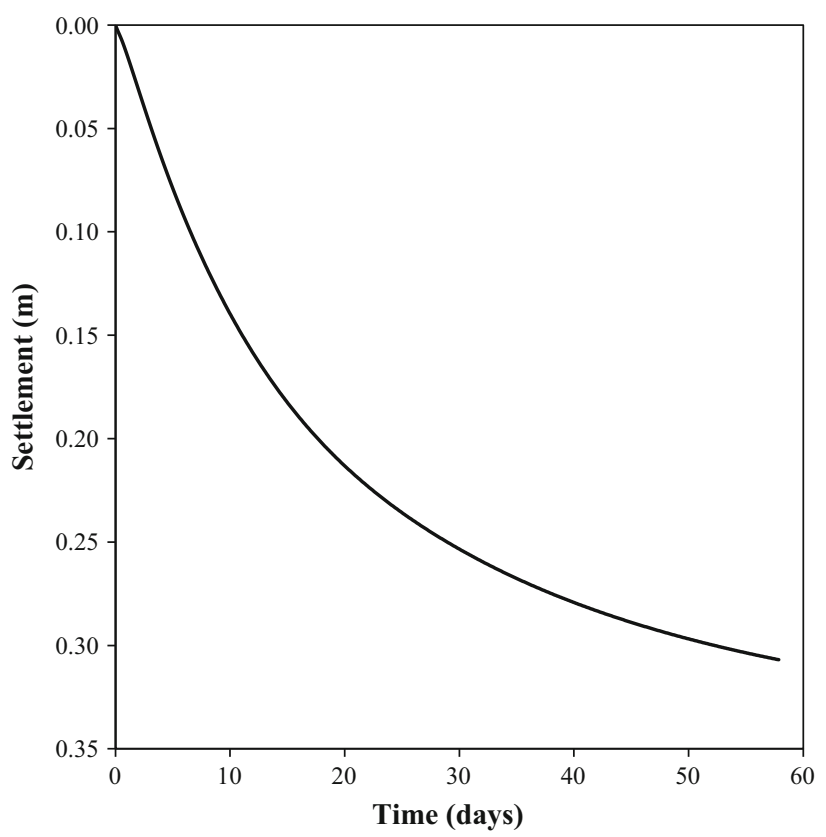

Fig. 9 Settlement versus time at the top of the anode

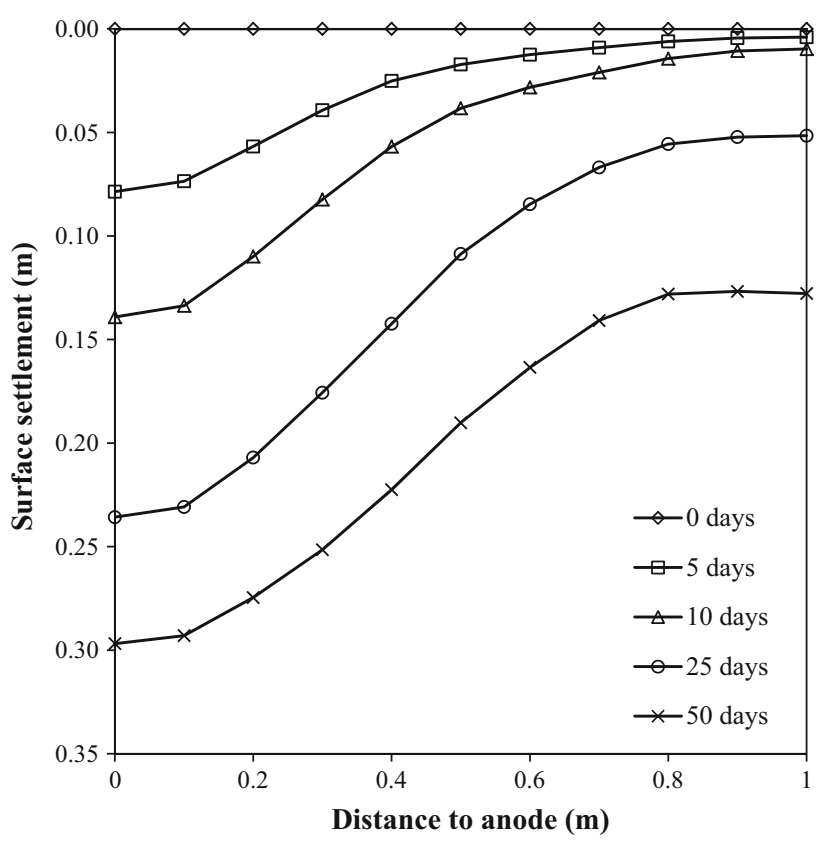

Fig. 10 Surface settlement relative to the anode at different times

The electric current through the sample is plotted as a function of time in Fig. 12, revealing that the current reduces from around 3.9 to $<2.8$ A during the simulation period. This is due to the void ratio decrease, during consolidation, causing an increase in the sample's resistance to the flow of electrical current. Figure 13 shows the initial and final voltage distributions along the bottom boundary between the two electrodes. The voltage drop near the 


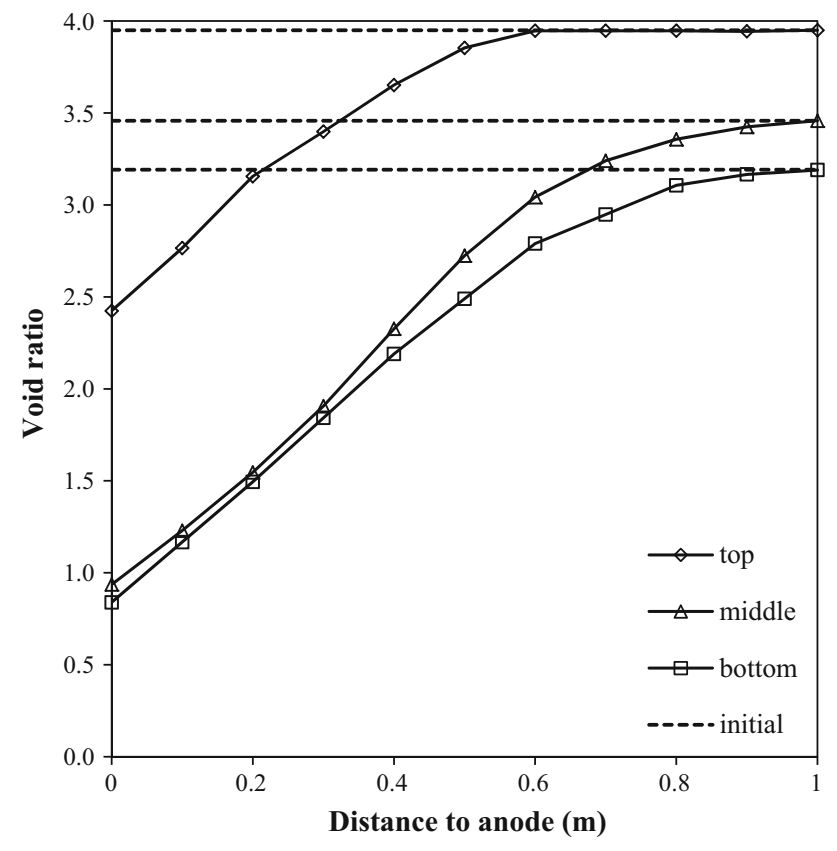

Fig. 11 Final void ratio profile relative to the anode at different depths

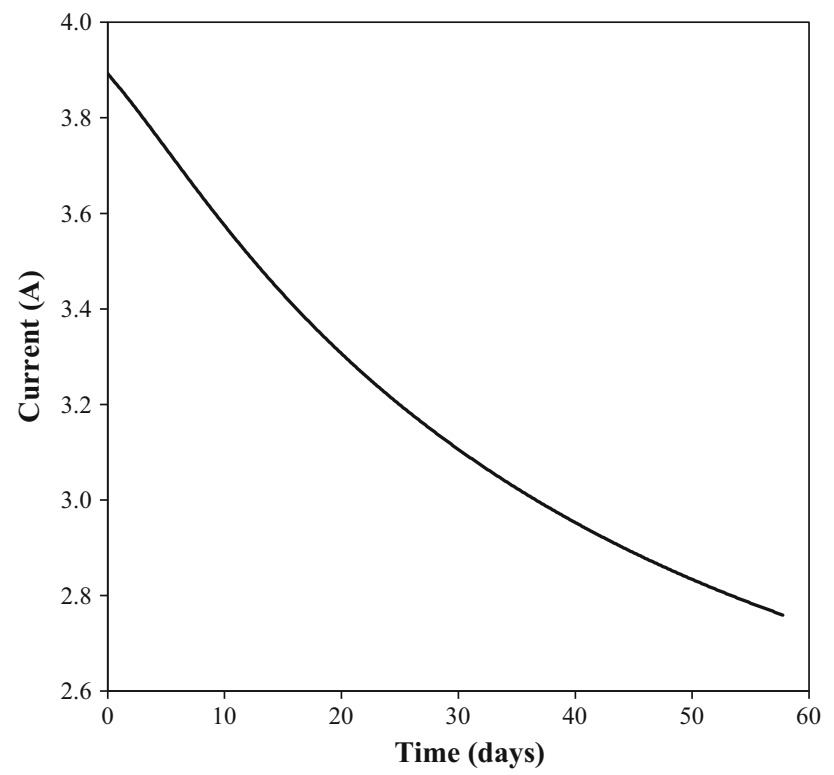

Fig. 12 Electric current versus time relationship

anode is due to the electrical conductivity decreasing with the increase of effective stress and is consistent with the findings of laboratory investigations [23, 32]. However, the voltage loss is not that significant, because, according to Eq. (49), the electric conductivity does not decrease rapidly with decreasing void ratio.

Figure 14 presents the initial and final pre-consolidation pressure distributions through the specimen, in which the

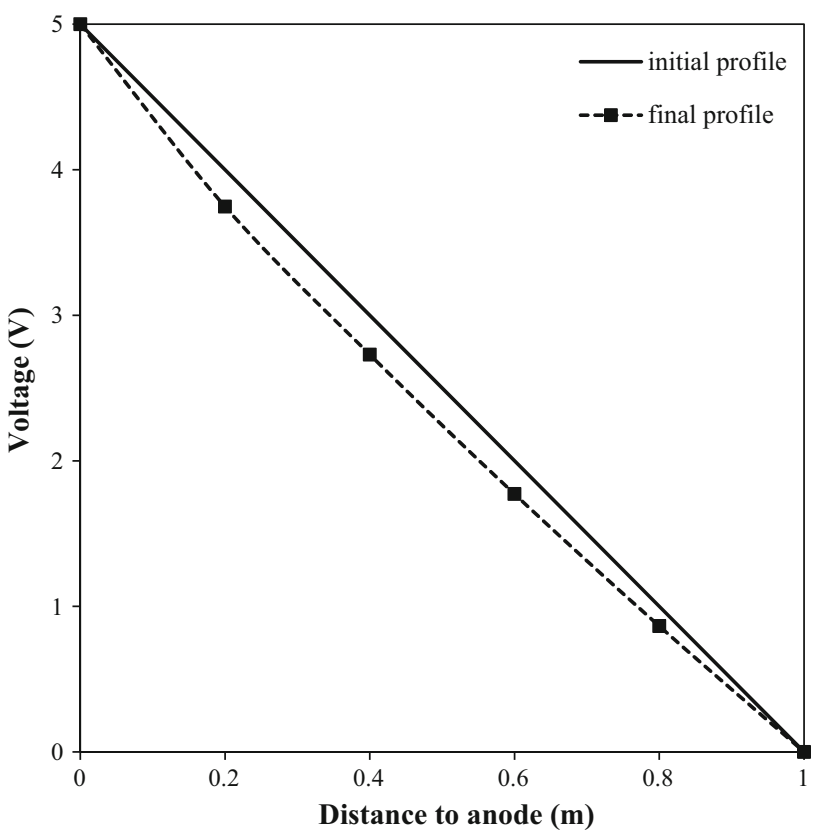

Fig. 13 Voltage profile along the bottom boundary relative to the anode

pre-consolidation pressure is defined by $p_{\mathrm{c}}$ in Eq. (22). It is seen that the gain in pre-consolidation pressure is much higher near the bottom of the anode than elsewhere. As the total vertical stress was kept constant during the electroosmosis consolidation, the increase in pre-consolidation pressure is approximately equal to the negative excess pore pressure developed. It is also noted that the increase in preconsolidation pressure near the top of the anode is much bigger than near the cathode where only a slight increase is observed. It is found that, by applying electro-osmosis consolidation, the strength improvement is not uniform; in this illustration, it is very efficient near the anode, but has almost no effect near the cathode.

\subsection{Numerical study of a field test}

A field test involving the electro-osmosis treatment of a Norwegian quick clay, reported by Bjerrum et al. [7], is simulated using finite element analysis to further verify the proposed numerical model. The test site was located in As, $30 \mathrm{~km}$ south of Oslo, Oslofjord, Norway. The test involved the installation of electrodes, of $10 \mathrm{~m}$ length and $19 \mathrm{~mm}$ diameter, arranged in 10 rows spaced $2 \mathrm{~m}$ apart. In each row, the electrodes (anodes or cathodes) were positioned at a spacing of $0.6-0.65 \mathrm{~m}$. They were pushed into the ground to a depth of about $9.6 \mathrm{~m}$, leaving $0.4 \mathrm{~m}$ above the ground, and three displacement gauges (S1, S2 and S3) were installed between the 4th and 5th electrode rows at depths of 1,4 and $8 \mathrm{~m}$, respectively. The DC voltage was applied 

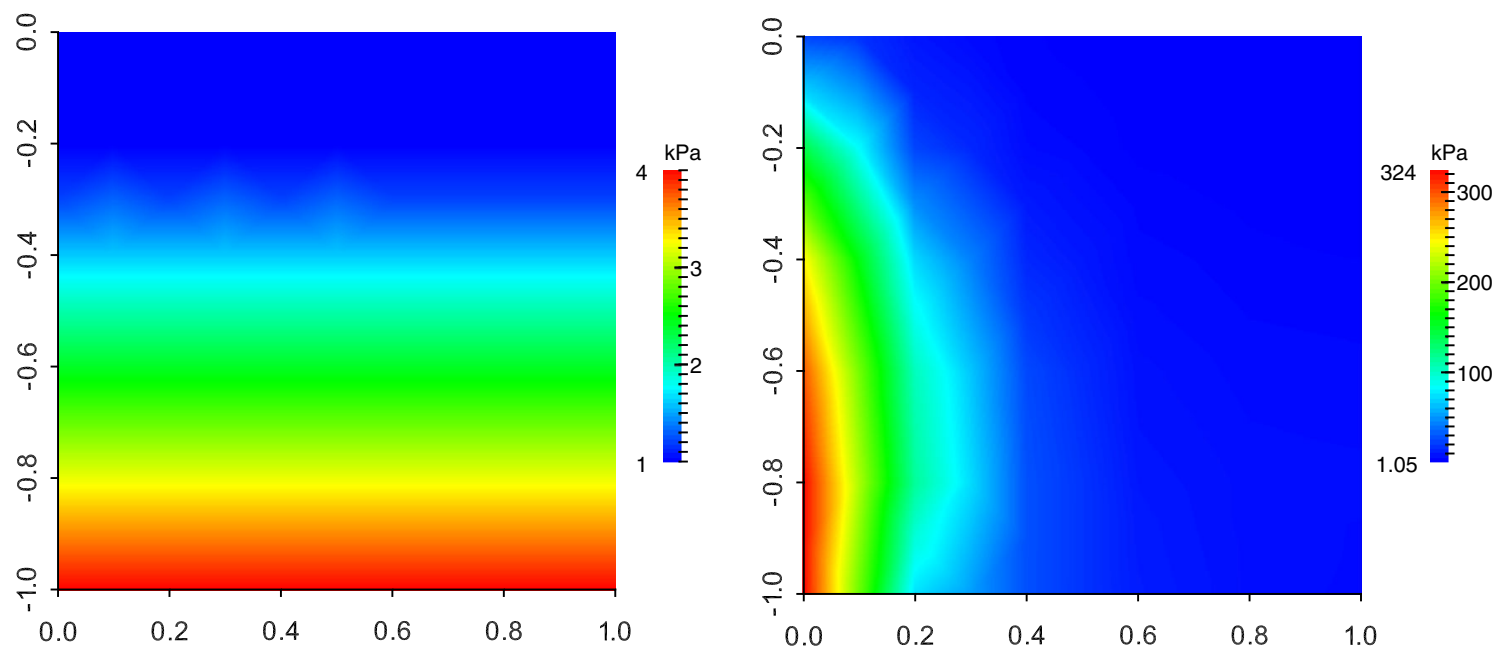

Fig. 14 Pre-consolidation pressure distributions: initial (left) and final (right)

for 120 days, but with current intermittence and polarity reversal.

The entire treatment area was subdivided into isolated repetitive areas, and so a $2 \mathrm{D}$ plane strain model is here adopted to simulate one repetitive area, as shown in Fig. 15. Note that the consolidation in the weathered crust making up the top $2 \mathrm{~m}$ is neglected, since it is a fairly stiff layer due to drying and weathering effects. Therefore, a rectangular domain of $2 \mathrm{~m}$ width and $7.6 \mathrm{~m}$ depth is simulated, with one impermeable anode and one drained cathode, as seen in the figure. The geotechnical properties of the soft clay, given in Table 3, are obtained directly from Bjerrum et al. [7], as are the electro-osmosis and hydraulic properties. Although Modified Cam Clay parameters were not stated in the paper, the plastic compression index $\lambda$ has been back-calculated from the given compression index, $C_{\mathrm{c}}=0.4$, using the relationship $\lambda=C_{\mathrm{c}} / 2.3=0.174$. Moreover, the ratio $\lambda / \kappa$ generally varies in the range $5-10$; in this analysis 6 is chosen, so that $\kappa=0.029$. For triaxial compression, the friction constant $M$ is calculated from the relationship $M=$ $6 \sin \phi /(3-\sin \phi)$; by assuming a friction angle of $15^{\circ}$, $M=0.567$. The Poisson's ratio is assumed to be 0.3 , whereas the initial effective stress and approximated preconsolidation pressure were given by Bjerrum et al. [7] and are shown in Fig. 16.

The applied voltage was not constant during the field test, since current intermittence and polarity reversal were considered. The applied voltage in the field test and the approximated input voltage are shown in Fig. 17. The voltage between the electrodes was measured on days 8,52 and 80 , and revealed a considerable potential drop within $10 \mathrm{~cm}$ of the electrodes. During the numerical simulation, the efficiency of the input voltage is considered to be approximately $75 \%$ before day 52 , and $50 \%$ during days $52-120$, based on the field measurements.

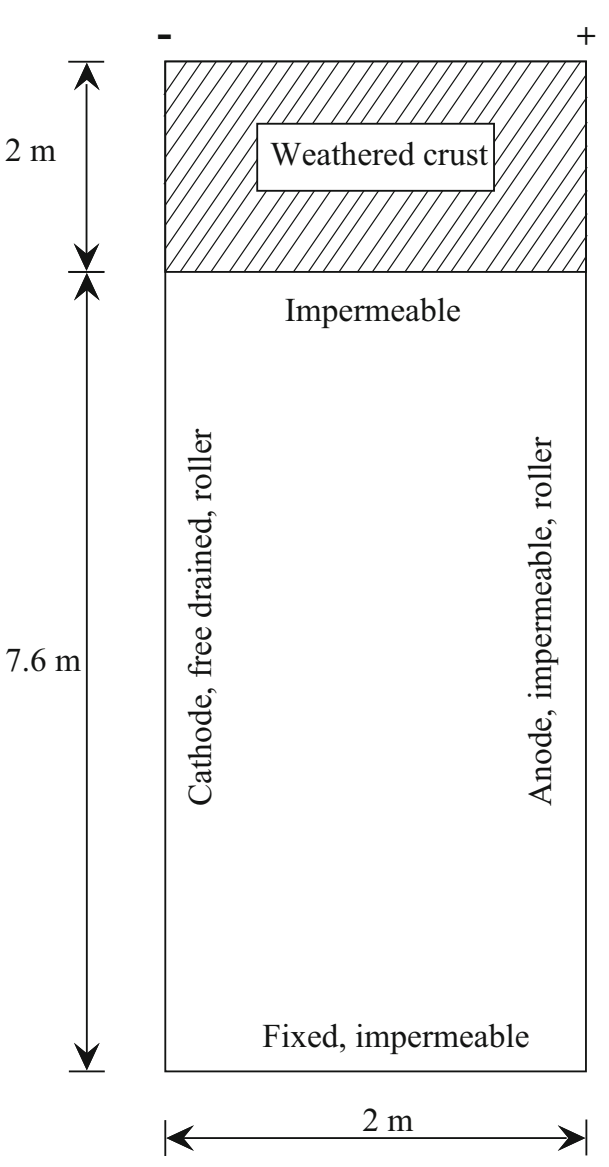

Fig. 15 Geometry and boundary conditions of the 2D model

The settlements at depths of 1,4 and $8 \mathrm{~m}$, computed in the large strain and small strain numerical analyses, as well as the field data from settlement gauges S1, S2 and S3 installed at the corresponding locations, are shown in Fig. 18. The results show that consideration of geometrical 
Table 3 Properties of soft clay (based on [7])

\begin{tabular}{lll}
\hline Natural water content & $w$ & $31 \%$ \\
Plastic limit & $w_{\mathrm{p}}$ & $14 \%$ \\
Liquid limit & $w_{\mathrm{L}}$ & $19 \%$ \\
Plastic index & $I_{\mathrm{p}}$ & $5 \%$ \\
Clay content $<2 \mu \mathrm{m}$ & - & $37 \%$ \\
Content of organic matter & - & $0.9 \%$ \\
Specific gravity & $G_{\mathrm{s}}$ & 2.75 \\
Compression index & $C_{\mathrm{c}}$ & 0.4 \\
Hydraulic conductivity & $k_{\mathrm{w}}$ & $2 \times 10^{-10} \mathrm{~m} / \mathrm{s}$ \\
Electro-osmosis permeability & $k_{\mathrm{eo}}$ & $2 \times 10^{-9} \mathrm{~m}^{2} /(\mathrm{V} \mathrm{s})$ \\
Electric conductivity & $k_{\sigma \mathrm{e}}$ & $0.0213 \mathrm{~S} / \mathrm{m}$ \\
\hline
\end{tabular}

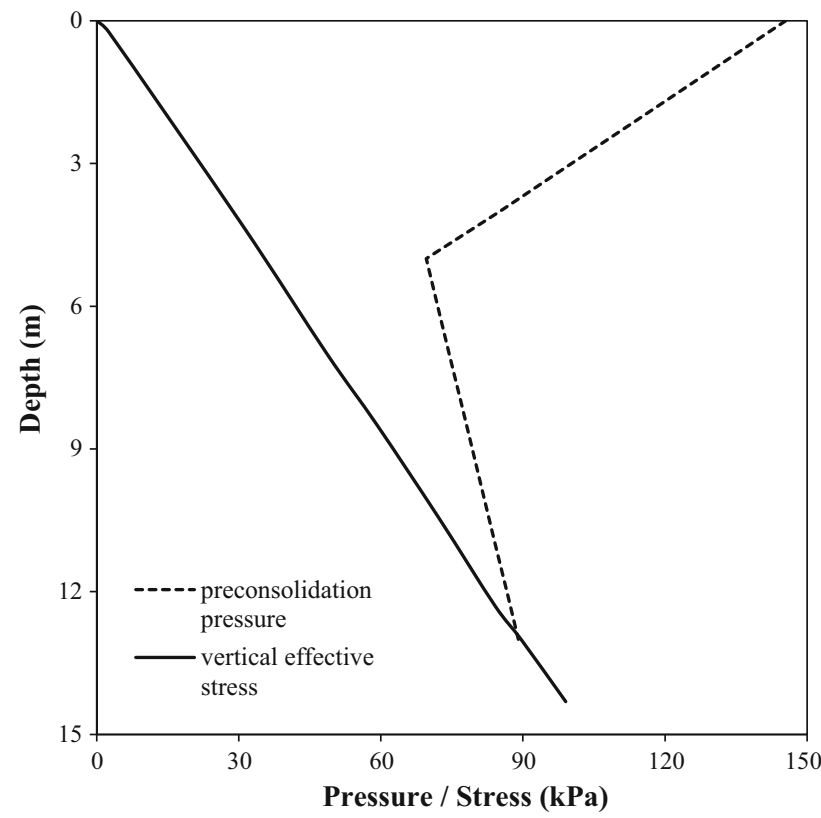

Fig. 16 Approximated initial effective stress and pre-consolidation pressure profiles (based on [7])

nonlinearity causes a reduction in the settlements relative to the small strain simulation and that this effect increases with time as the consolidation progresses. However, the differences between the two solutions are relatively small in this example. This is because, although the settlements are as high as $0.6 \mathrm{~m}$, the strains are only moderate due to the overall thickness of the layer.

Figure 18 shows excellent agreement between the computed and measured settlements, especially for the first 70 days of the treatment period, at depths of 1 and $8 \mathrm{~m}$. However, the computed settlement at $4 \mathrm{~m}$ depth is smaller than the measured settlement. The computed settlements are larger than the measured values between days 70 and 120, at both 1 and $8 \mathrm{~m}$ depth. Finally, current intermittence and current reversal are considered in the analysis. As can

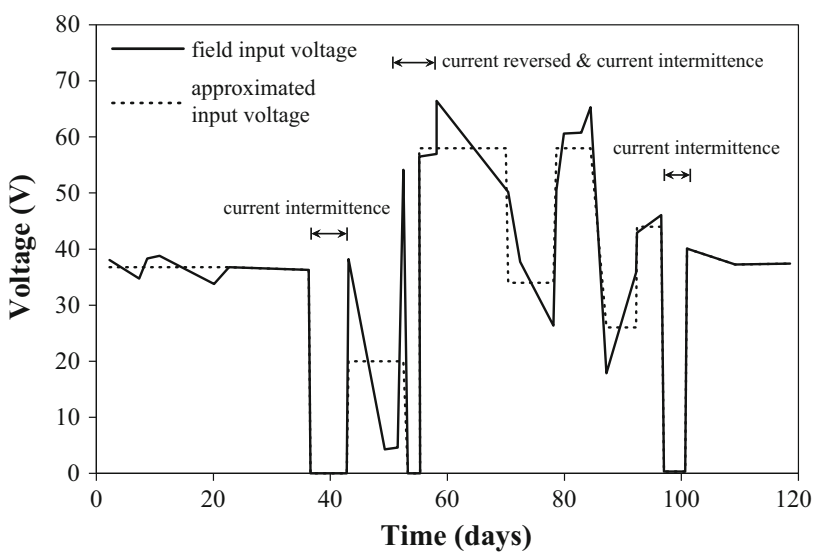

Fig. 17 Applied field and approximated input voltages versus time (based on [7])

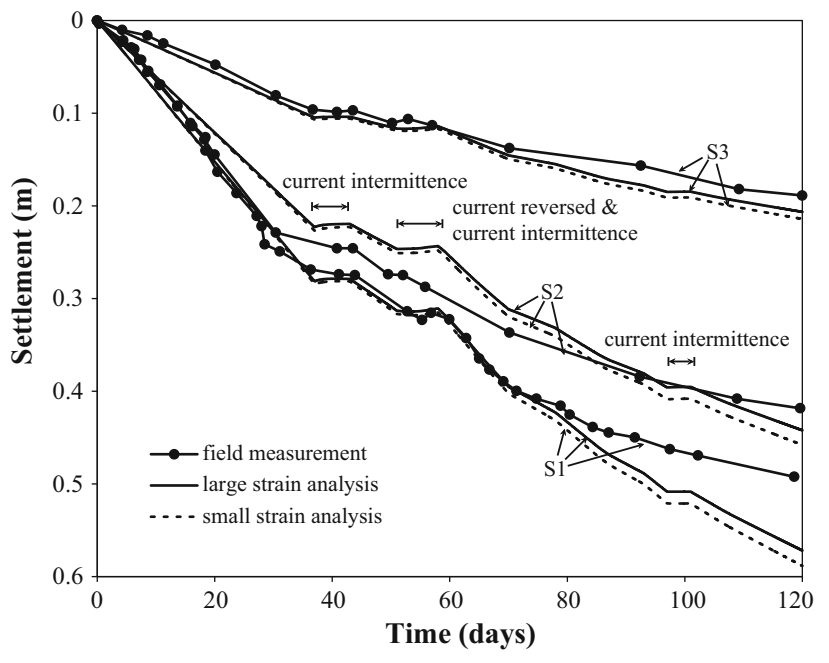

Fig. 18 Computed and measured settlement versus time at different depths

be seen in Fig. 18, the impact of the current intermittence between days 37 and 43, and the current intermittence and reversal between days 51 and 58, have been well reproduced by the numerical simulation.

\section{Conclusions}

A formulation for the consideration of large strain elastoplastic electro-osmosis consolidation has been presented. Three coupled governing equations for force equilibrium, pore water transport and electrical transport are derived and solved using finite elements. The elasto-plastic behaviour of clay is considered by employing the Modified Cam Clay constitutive model, and nonlinear variations in soil transport parameters are incorporated by introducing a dependence of the absolute soil conductivity or permeability 
(with respect to hydraulic, electro-osmosis and electrical model components) on void ratio.

The proposed approach has been verified against a 1D large strain electro-osmosis consolidation test, and the numerical results show good agreement with the experimental data. Following the verification, the performance and applicability of the approach has been demonstrated via three further numerical examples. A simple 1D numerical simulation was conducted and evaluated, to highlight the influence of considering large strain during electro-osmosis consolidation. An idealized 2D electro-osmosis consolidation problem, using the Modified Cam Clay constitutive relationship, was then investigated. Changes in void ratio, and consequent changes in the coefficients of hydraulic conductivity and electro-osmosis permeability during the electro-osmosis consolidation, could not be neglected, because the coefficients of hydraulic conductivity and electro-osmosis permeability are two of the dominating factors in the consolidation process. Furthermore, the voltage and current distributions were investigated, by considering the change in the electrical conductivity. It was demonstrated that the voltage drop near the anode, and the current decrease during electro-osmosis which has been found in many laboratory tests, can be simulated by the proposed model. Moreover, the strength improvement in the clay during the electro-osmosis was quantified. A significant improvement in the pre-consolidation pressure was found in the vicinity of the anode. Finally, a field test of electro-osmosis treatment was analysed, to further demonstrate the capability of the proposed numerical model. The computed settlement at different depths showed good agreement with the measured data.

The presented numerical examples have demonstrated that the modelling of electro-osmosis consolidation has to be performed carefully, according to realistic conditions. Hence the consideration of large strain elasto-plastic mechanical behaviour and nonlinear soil transport properties is often necessary.

Acknowledgments This research has been supported by the China Scholarship Council (CSC) and by the Section of Geo-Engineering at Delft University of Technology.

Open Access This article is distributed under the terms of the Creative Commons Attribution License which permits any use, distribution, and reproduction in any medium, provided the original author(s) and the source are credited.

\section{Appendix}

The coefficient matrices in the set of discretized governing equations, Eq. (42), are defined as follows:
Elasto-plastic stiffness matrix for small deformation:

$\mathbf{K}_{\mathrm{ep}}=\int_{V} \mathbf{B}_{\mathrm{L}}^{\mathrm{T}} \mathbf{D}_{\mathrm{ep}} \mathbf{B}_{\mathrm{L}} \mathrm{d} V$

where $V$ is the volume.

Geometric stiffness matrix:

$\mathbf{K}_{\mathrm{g}}=\int_{V} \mathbf{B}_{\mathrm{L}}^{\mathrm{T}} \overline{\boldsymbol{\sigma}} \overline{\mathbf{B}}_{\mathrm{L}} \mathrm{d} V+\int_{V} \mathbf{B}_{\mathrm{NL}}^{\mathrm{T}} \mathbf{p} \mathbf{B}_{\mathrm{NL}} \mathrm{d} V+\int_{V} \mathbf{B}_{\mathrm{NL}}^{\mathrm{T}} \boldsymbol{\sigma}^{\prime} \mathbf{B}_{\mathrm{NL}} \mathrm{d} V$

where $\mathbf{B}_{\mathrm{L}}, \overline{\mathbf{B}}_{\mathrm{L}}$ and $\mathbf{B}_{\mathrm{NL}}$ are the strain-displacement operators, and $\overline{\boldsymbol{\sigma}}, \boldsymbol{\sigma}^{\prime}$ and $\mathbf{p}$ are the stress matrix caused by rotation, the effective stress matrix and the pore pressure matrix, respectively.

Global coupling matrix:

$\mathbf{L}=\int_{V} \mathbf{B}_{\mathrm{L}}^{\mathrm{T}} \mathbf{I} \mathbf{N}_{p} \mathrm{~d} V$

External loads vector:

$\mathbf{F}^{\mathrm{ext}}=\int_{S} \mathbf{N}_{\mathbf{u}}^{\mathrm{T}} \mathbf{t d} S+\int_{V} \mathbf{N}_{\mathbf{u}}^{\mathrm{T}} \mathbf{b} \mathrm{d} V$

where $\mathbf{t}$ are the prescribed surface tractions, $\mathbf{b}$ are the body forces and $S$ is the surface.

Hydraulic flow matrix:

$\mathbf{K}_{\mathrm{c}}=-\int_{V} \gamma_{\mathrm{w}}^{-1} \cdot \mathbf{B}_{p}^{\mathrm{T}} \mathbf{k}_{\mathrm{w}} \mathbf{B}_{p} \mathrm{~d} V$

where $\mathbf{B}_{p}$ is the matrix containing the gradients of the pore pressure shape functions $\mathbf{N}_{p}$, and $\mathbf{k}_{\mathrm{w}}$ is the hydraulic conductivity matrix.

Electro-osmosis flow matrix:

$\mathbf{K}_{\mathrm{eo}}=-\int_{V} \mathbf{B}_{p}^{\mathrm{T}} \mathbf{k}_{\mathrm{eo}} \mathbf{B}_{V} \mathrm{~d} V$

where $\mathbf{B}_{V}$ is the matrix of the gradients of the electric potential shape functions $\mathbf{N}_{V}$, and $\mathbf{k}_{\mathrm{eo}}$ is the electro-osmosis permeability matrix.

External fluid supply vector:

$\mathbf{Q}_{p}^{\text {ext }}=\int_{S} \mathbf{N}_{p}^{\mathrm{T}} \mathbf{q}_{\mathrm{w}} \mathrm{d} S$

where $\mathbf{q}_{\mathrm{w}}$ is the prescribed surface flux.

Current flux matrix:

$\mathbf{K}_{\sigma \mathrm{e}}=\int_{V} \mathbf{B}_{V}^{\mathrm{T}} \mathbf{k}_{\sigma \mathrm{e}} \mathbf{B}_{V} \mathrm{~d} V$

where $\mathbf{k}_{\sigma \mathrm{e}}$ is the electrical conductivity matrix. 
External current supply vector:

$\mathbf{Q}_{V}^{\text {ext }}=\int_{S} \mathbf{N}_{V}^{\mathrm{T}} \mathbf{q}_{\mathrm{e}} \mathrm{d} S$

where $\mathbf{q}_{\mathrm{e}}$ is the prescribed surface current flux.

\section{References}

1. Acar YB, Alshawabkeh AN (1996) Electrokinetic remediation. I: pilot-scale tests with lead-spiked kaolinite. J Geotech Eng 122(3):173-185

2. Airoldi F, Jommi C, Musso G, Paglino E (2009) Influence of calcite on the electrokinetic treatment of a natural clay. J Appl Electrochem 39(11):2227-2237

3. Alshawabkeh AN, Acar YB (1996) Electrokinetic remediation. II: theoretical model. J Geotech Eng 122(3):186-196

4. Alshawabkeh AN, Sheahan TC (2003) Soft soil stabilisation by ionic injection under electric fields. Proc ICE Ground Improv 7(4):177-185

5. Alshawabkeh AN, Yeung AT, Bricka MR (1999) Practical aspects of in situ electrokinetic extraction. J Environ Eng ASCE 125(1):27-35

6. Bergado DT, Sasanakul I, Horpibulsuk S (2003) Electro-osmotic consolidation of soft Bangkok clay using copper and carbon electrodes with PVD. Geotech Test J 26(3):277-288

7. Bjerrum L, Moum J, Eide O (1967) Application of electroosmosis to a foundation problem in a Norwegian quick clay. Géotechnique 17(3):214-235

8. Burnotte F, Lefebvre G, Grondin G (2004) A case record of electroosmotic consolidation of soft clay with improved soil electrode contact. Can Geotech J 41(6):1038-1053

9. Carter JP, Small JC, Booker JR (1977) A theory of finite elastic consolidation. Int J Solids Struct 13(5):467-478

10. Casagrande L (1952) Electro-osmotic stabilization of soils. J Boston Soc Civ Eng ASCE 39(1):51-83

11. Casagrande L (1983) Stabilization of soils by means of electroosmosis-state of the art. J Boston Soc Civ Eng ASCE 69(2):255-302

12. Cattaneo F, Jommi C, Musso G (2010) A numerical model for the electrokinetic treatment of natural soils with calcite. In: Numerical methods in geotechnical engineering. CRC Press, Boca Raton, FL, pp 275-280

13. Chappell BA, Burton PL (1975) Electro-osmosis applied to unstable embankment. J Geotech Eng Div ASCE 101(8):733-740

14. Chen H, Mujumdar AS, Raghavan GSV (1996) Laboratory experiments on electroosmotic dewatering of vegetable sludge and mine tailings. Dry Technol 14(10):2435-2445

15. Chu J, Varaksin S, Klotz U, Menge P (2009) Construction processes, state of the art report. In: 17th International conference on soil mechanics and geotechnical engineering, Alexandria, Egypt, pp 3006-3135

16. de Borst R, Crisfield MA, Remmers JJC, Verhoosel CV (2012) Non-linear finite element analysis of solids and structures, 2nd edn. Wiley, Chichester

17. De Souza Neto EA, Perić D, Owen DRJ (2008) Computational methods for plasticity: theory and applications. Wiley, Chichester

18. Esrig MI (1968) Pore pressures, consolidation and electrokinetics. J Geotech Eng Div ASCE 94(4):899-921

19. Feldkamp JR, Belhomme GM (1990) Large-strain electrokinetic consolidation: theory and experiment in one dimension. Géotechnique 40(4):557-568
20. Fetzer CA (1967) Electro-osmotic stabilization of West Branch Dam. J Soil Mech Found Div ASCE 93(4):85-106

21. Fourie AB, Johns DG, Jones CJFP (2007) Dewatering of mine tailings using electrokinetic geosynthetics. Can Geotech J 44(2):160-172

22. Gray DH (1970) Electrochemical hardening of clay soils. Géotechnique 20(1):81-93

23. Lefebvre G, Burnotte F (2002) Improvements of electroosmotic consolidation of soft clays by minimizing power loss at electrodes. Can Geotech J 39(2):399-408

24. Lewis RW, Garner RW (1972) A finite element solution of coupled electrokinetic and hydrodynamic flow in porous media. Int J Numer Methods Eng 5(1):41-55

25. Lewis RW, Schrefler BA (1998) The finite element method in the static and dynamic deformation and consolidation of porous media, 2nd edn. Wiley, Chichester

26. Lin B, Cerato AB (2013) Electromagnetic properties of natural expansive soils under one-dimensional deformation. Acta Geotech 8(4):381-393

27. Lo KY, Ho KS, Inculet II (1991) Field test of electroosmotic strengthening of soft sensitive clay. Can Geotech J 28(1):74-83

28. Lockhart NC, Hart GH (1988) Electro-osmotic dewatering of fine suspensions: the efficacy of current interruptions. Dry Technol 6(3):415-423

29. Meroi EA, Schrefler BA, Zienkiewicz OC (1995) Large strain static and dynamic semisaturated soil behaviour. Int $\mathrm{J}$ Numer Anal Methods Geomech 19(2):81-106

30. Milligan V (1995) First application of electro-osmosis to improve friction pile capacity - three decades later. Geotech Eng Proc ICE 113(2):112-116

31. Mitchell JK, Soga K (2005) Fundamentals of soil behavior, 3rd edn. Wiley, Hoboken, NJ

32. Mohamedelhassan E, Shang JQ (2001) Effects of electrode materials and current intermittence in electro-osmosis. Proc ICE Ground Improv 5(1):3-11

33. Mohamedelhassan E, Shang JQ (2002) Feasibility assessment of electro-osmotic consolidation on marine sediment. Proc ICE Ground Improv 6(4):145-152

34. Nazem M, Sheng D, Carter JP (2006) Stress integration and mesh refinement for large deformation in geomechanics. Int $\mathrm{J}$ Numer Methods Eng 65(7):1002-1027

35. Nazem M, Sheng D, Carter JP, Sloan SW (2008) Arbitrary Lagrangian-Eulerian method for large-strain consolidation problems. Int J Numer Anal Methods Geomech 32(9):1023-1050

36. Nazem M, Carter JP, Sheng D, Sloan SW (2009) Alternative stress-integration schemes for large-deformation problems of solid mechanics. Finite Elem Anal Des 45(12):934-943

37. Nicholls RL, Herbst RL (1967) Consolidation under electricalpressure gradients. J Soil Mech Found Div ASCE 93(5):139-151

38. Ou CY, Chien SC, Chang HH (2009) Soil improvement using electroosmosis with the injection of chemical solutions: field tests. Can Geotech J 46(6):727-733

39. Rittirong A, Shang JQ (2008) Numerical analysis for electroosmotic consolidation in two-dimensional electric field. In: Proceedings of the 18th international offshore and polar engineering conference, Vancouver, 2008, pp 566-572

40. Roscoe KH, Burland JB (1968) On the generalized stress-strain behaviour of 'wet' clay. In: Heyman J, Leckie FA (eds) Engineering plasticity. Cambridge University Press, London, pp 535-609

41. Roscoe KH, Schofield AN, Thurairajah A (1963) Yielding of clays in states wetter than critical. Géotechnique 13(3):211-240

42. Shang JQ (1998) Electroosmosis-enhanced preloading consolidation via vertical drains. Can Geotech J 35(3):491-499

43. Shang JQ (1998) Two-dimensional electro-osmotic consolidation. Proc ICE Ground Improv 2(1):17-25 
44. Sheng D, Sloan SW (2003) Time stepping schemes for coupled displacement and pore pressure analysis. Comput Mech 31(1-2 SPEC):122-134

45. Smith IM, Griffiths DV (2004) Programming the finite element method, 4th edn. Wiley, Chichester

46. Tamagnini C, Jommi C, Cattaneo F (2010) A model for coupled electro-hydro-mechanical processes in fine grained soils accounting for gas generation and transport. An Acad Bras Ciênc 82(1):169-193

47. Wan T, Mitchell JK (1976) Electroosmotic consolidation of soils. J Geotech Eng Div ASCE 101(5):503-507
48. Yeung AT (2006) Contaminant extractability by electrokinetics. Environ Eng Sci 23(1):202-224

49. Yuan J, Hicks MA (2013) Large deformation elastic electroosmosis consolidation of clays. Comput Geotech 54:60-68

50. Yuan J, Hicks MA, Dijkstra J (2012) Multi-dimensional electroosmosis consolidation of clays. In: Proceedings of the international symposium on ground improvement, Brussels, Belgium, pp 241-248

51. Yuan J, Hicks MA, Dijkstra J (2013) Numerical model of elastoplastic electro-osmosis consolidation of clays. In: Poromechanics V, Vienna, Austria. ASCE, pp 2076-2085 